\title{
Ganoderma - A therapeutic fungal biofactory
}

\author{
R. Russell M. Paterson \\ Micoteca da Universidade do Minho, Centro de Engenharia Biológica, Campus de Gualtar, 4710-057 Braga, Portugal
}

Received 21 March 2006; received in revised form 1 July 2006

Available online 14 August 2006

\begin{abstract}
Ganoderma is a basidiomycete white rot fungus which has been used for medicinal purposes for centuries particularly in China, Japan and Korea. A great deal of work has been carried out on Ganoderma lucidum. The common names for preparations include Lingzhi, Munnertake, Sachitake, Reishi and Youngzhi. This review collates the publications detailing activities and compounds by representative species whilst considering the most valid claims of effectiveness. The biological activities reported of preparations from Ganoderma are remarkable and given most emphasis herein as distinct from structure/activity information. The metabolites consist of mainly polysaccharides and terpenoids. Many are activities against the major diseases of our time and so the present review is of great importance. The list of effects is huge ranging from anti-cancer to relieving blockages of the bladder. However, the reports have not all been tested scientifically with the convincing evidence is reserved for assays of pure compounds. It is a prime example of an ancient remedy being of great relevance to the modern era. There does appear to be an assumption that the therapeutic effects attributed to the fungus have been proven. The next step is to produce some effective medicines which may be hampered by problems of mass production.
\end{abstract}

(c) 2006 Elsevier Ltd. All rights reserved.

Keywords: Ganoderma; Polyporaceae; Lingzhi; Terpenoids; Steroids; Polysaccharides; Cancer; HIV

\section{Contents}

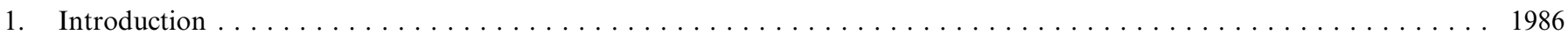

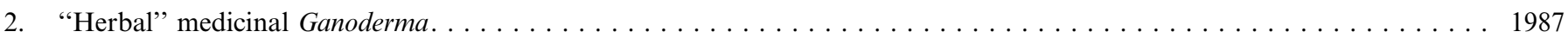

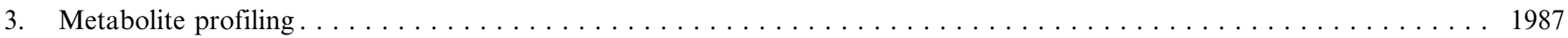

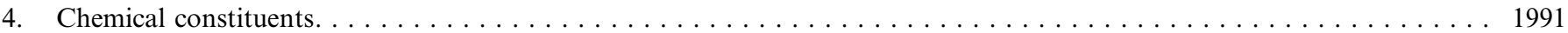

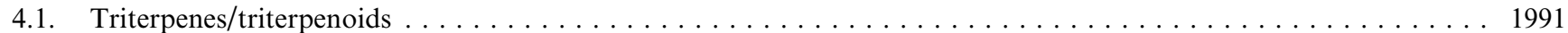

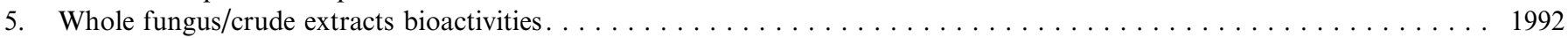

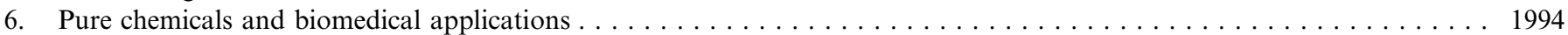

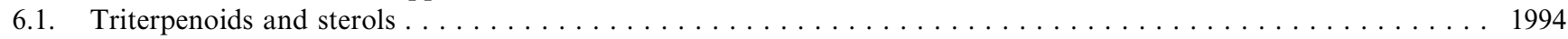

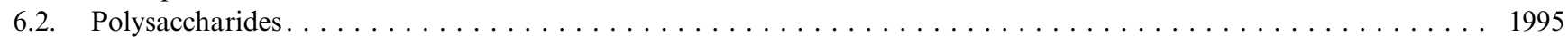

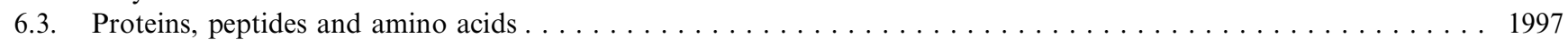

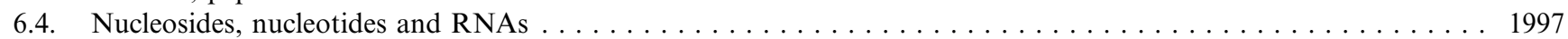

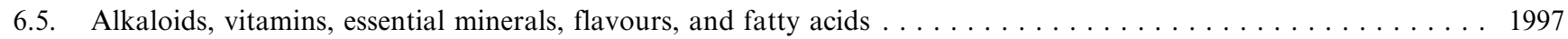

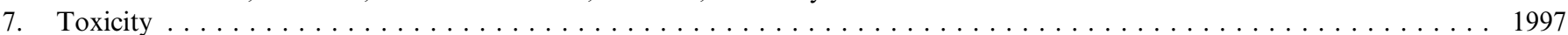

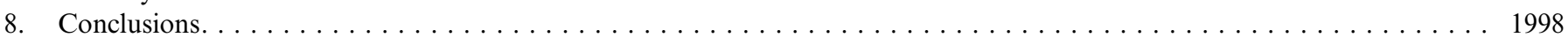

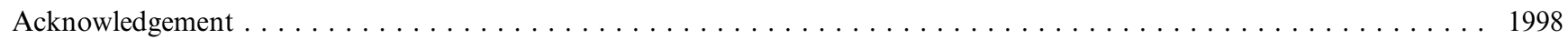

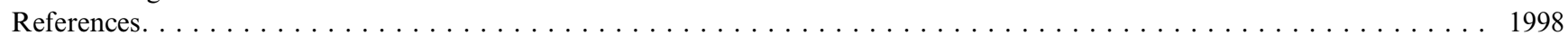

E-mail address: russell.paterson@deb.uminho.pt 


\section{Introduction}

Ganoderma is a prolific producer of novel "mycochemicals". The quantity of information on the fungus in this respect is quite remarkable; hence this is an extensive review. However, there is an uneasy combination of the mythical, pseudo-science and science and deciding one from the other requires experience. The organism is a white rot which is involved in the fundamental process of lignocellulose degradation in Nature, although this aspect will not be considered. An image of a Ganoderma specimen is provided in Fig. 1 and appears to be G. applanatum from the morphology alone. The Chinese, inter alia, have used preparations as medicines from a similar or identical fungus, for millennia (cited as early as $100 \mathrm{BC}$ ) and have given the organism the name "Lingzhi". In Japan the names include Munnertake, Sachitake and Reishi, whereas in Korea it has the name Youngzhi. However, whether this and any particular species of Ganoderma represent the same entity and throughout all periods in history is questionable. The taxonomic situation within Ganoderma is unclear as the species and genus concepts are confused. For example, similar fungi are found in Fomes, Polyporus and Tomophagus.

"Lingzhi" is the Chinese name given to the basiocarps (my preferred name) of Ganoderma as isolated in that vast and diverse country. However, there is a tendency for authors in the scientific literature to refer to such names making definitive conclusions more difficult (see Huie and $\mathrm{Di}, 2004)$. The preparation was and is considered to have healing properties to the body and mind: "Lingzhi" is still revered by some. The preparation does indeed contain certain bioactive ingredients (such as triterpenes and polysaccharides) that might be beneficial for the prevention and treatment of a variety of ailments. Remarkably, these include such very important diseases such as hypertension, diabetes, hepatitis, cancers, and AIDS. These types of biomedical investigations have been conducted predominately in China, Korea, Japan and the United States of America and so are extensive. It is unclear why other countries are not more involved.

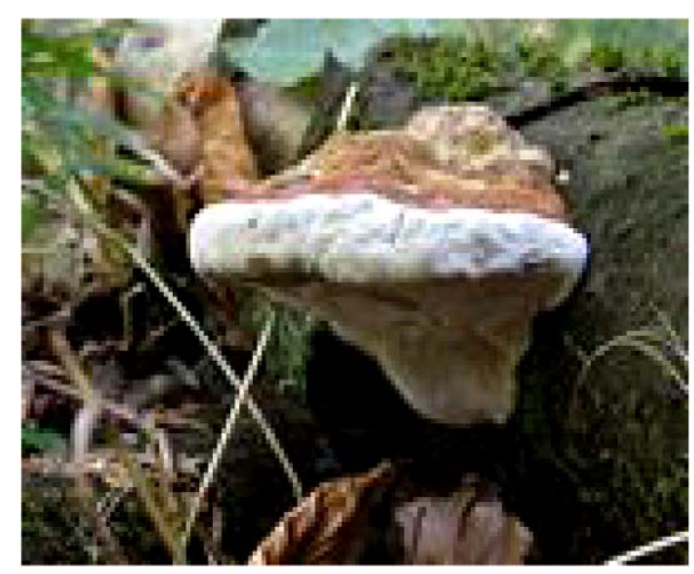

Fig. 1. A typical Ganoderma basidiocarp.
Research, quality assurance and control of "Lingzhi" products depend on the isolation/purification of active ingredients and analytical/preparative separations (Huie and $\mathrm{Di}, 2004)$. A practical classification of the fungus is required to understand more clearly what the fungus represents. In addition, research is necessary on the physiology of production of the active metabolites to enable yields to be optimised in solid or liquid substrate bioreactors assuming they can be so produced.

Preparations referred to as "Lingzhi" were/are used widely as a health supplement and "herbal" medicine worldwide. Of course, the fungus is not a herb (which are plants) and calling it such simply adds to the confusions surrounding names. A company in the USA has a web site with numerous Ganoderma products which makes extraordinary claims for medicinal properties (http://www.fungi.$\mathrm{com} /$ ). This raises issues of accreditation and validity. However, strapped-for-cash culture collections will look enviously at the commercial potential. Employing my computer search engine gave numerous "hits" from organisations selling such preparations which must surely be of concern to those in search of valid data.

As indicated previously, there are issues that require to be addressed in relation to the fungus: What is Ganoderma? How does it relate to Fomes, Polyporus, and Tomophagus? What constitute the preparations with non-Latinised names that are often referred to (e.g. Lingzhi, Songshan lingzhi, Reishi)? After all, these are the ancient medicines on which all the new research and interest are based. Have voucher specimens of Ganoderma been placed in culture collections with international accreditation, and are they available to others (see Paterson, 2005)? How useful is the information in obscure journals? Using only one sample for species recognition as has occurred (e.g. Di et al., 2003) and is invalid as assessments of variation cannot be obtained.

For example, a G. lucidum has been worked on extensively and yet was obtained from the family-owned company mentioned previously (see Ziegenbein et al., 2006). What degree of scientific accreditation applies to this private enterprise? The same questions can be asked of other culture collections, whether public or private, where high quality accessions, preservation and identifications may not apply: A culture collection in China will not necessarily have the equivalent standards to one in the USA.

"Lingzhi" has been examined predominantly for bioactive triterpenes and polysaccharides. It is perhaps surprising that other classes of intrinsically secondary metabolites have not been found. For example, polyketides and shikimic acid pathway metabolites are not well represented. A point to consider is that the fungus may transform compounds from the host on which it was isolated and not be able to produce the compounds per se. This may be true particularly of lignin-derived compounds as the white rot fungi degrade lignin to monomeric phenols and further to $\mathrm{CO}_{2}$ and $\mathrm{H}_{2} \mathrm{O}$ for energy (Leonowicz et al., 1999) which will have ramifications for mass production of treatments. 
The use of the term "Lingzhi" needs to be avoided in scientific papers (cf. Huie and Di, 2004) as it is imprecise and the Latin names should prevail. I will tend to use inverted commas when referring to it as a compromise. "Lingzhi" has been used for the treatment of migraine, hypertension, arthritis, bronchitis, asthma, anorexia, gastritis, haemorrhoids, diabetes, hypercholesterolaemia, nephritis, dysmenorrhoea, constipation, lupus erythematosis, hepatitis, and cardiovascular problems. One can only wonder how the treatments were assessed as being effective. It is claimed to possess (a) anti-cancer (including leukaemia), (b) anti-ageing and (c) anti-microbial/viral activities including anti-human immunodeficiency virus (HIV). Additionally, the presence of neuroactive compounds in the extracts of "Lingzhi" that mediated the neuronal differentiation and neuroprotection of rat $\mathrm{PC} 12$ cells has also been demonstrated recently (Huie and Di, 2004). This all seems like very good news indeed as even one of these effects would be remarkable if some new prescribed medicines were produced. Extraordinary claims such as these needs to have equivalent evidence to prove that they are factual.

Furthermore, Ganoderma is not a herb as mentioned previously: It is a complex fungus which has had very significant interactions with human beings over the centuries. The label "herb" needs to be avoided. Fungi form a separate kingdom from plants and are closer to animals in an evolutionary sense. These definitions are important. For example, Ganoderma is not likely to contain lignin but this is what is implied in Huie and Di (2004) in an interpretation of how an enzyme-based extraction procedure is effective. The enzyme was claimed to break bonds between cellulose and lignin hence permitting the extraction of the desired material. And so the rational for the extraction procedure with enzymes was wrong from the initial assumption. The following review will consider how the fungus became to be known as an ancient remedy for ailments and what the latest developments have been. Extensive references are provided because of the huge claims beings made of the biomedical activities of Ganoderma.

\section{2. "Herbal" medicinal Ganoderma}

Sliva (2006) and Stanley et al. (2005) mention that $G$. lucidum is a popular medicinal mushroom, and has been used in traditional Chinese medicine (TCM) in Asian countries over the past two millennia. The regular consumption was/is believed to preserve human vitality and to promote longevity. The fungus has been used for the prevention, or treatment, of numerous diseases including cancer although whether it was effective is presumably unknown. Western medicine began to study natural products from TCM and the popularity of herbal therapies for the treatment of cancer has increased in the USA. Of course, Ganoderma is a fungus and not a herb. Scientific elucidation of mechanisms responsible for the biological effects of these natural products would indicate if they were valid alternatives, or adjuvant cancer therapies; as would well-conducted therapeutic trials.

Furthermore, Chen et al. (2006) in an extensive paper mention that many "herbal" medicines are used widely as immuno-modulators in Asian countries. G. lucidum is one of the most used "herbs" in Asia and preclinical studies have established that the polysaccharide fractions have potent effects. Also, one wonders what "established" means here - is it proven? As mentioned, clinical evidence for this is scarce. Pero et al. (2005) state that, the combination of nutritional supplements to achieve synergistic benefit is a common practice in the nutraceutical industry. However, establishing added health benefit from a combination of natural ingredients is often assumed, untested and without regard to the principle of metabolic competition between the active components (see Aydemir, 2002).

The dried powder is currently used worldwide in the form of dietary supplements. Stanley et al. (2005) have demonstrated that G. lucidum induces apoptosis, inhibits cell proliferation, and suppresses cell migration of highly invasive human prostate cancer cells PC-3. However, the molecular mechanism(s) responsible for the inhibitory effects have not been fully elucidated. Hajjaj et al. (2005) state that G. lucidum is a medicinal fungus belonging to the Polyporaceae family and is know in Japan as Reishi. Furthermore, Müller et al. (2006) emphasise that over many centuries, "herbal" remedies have treated a variety of ailments and the empirical/observational approach has produced a number of leads for formulated medicines. Lin et al. (2006) refer to G. tsugae as the Chinese mushroom Songshan lingzhi, which is cultivated in Taiwan and used extensively to treat diseases. Johnston (2005) alludes to the fact that G. lucidum is used in TCM for the treatment of cancers. In truth, the fungus must be one of the most convincing examples of ancient folk remedies being translated into new drug leads, and may represent an excellent paradigm for the general principal. Screening methods are very useful for assessing the constituents of preparations before the isolation of compounds and this is next presented.

\section{Metabolite profiling}

Differentiation was possible of "Lingzhi" from several other fungal crude drugs, such as hoelen, omphalia and polyporus using TLC (Huie and Di, 2004). Ganoderic acids B and $\mathrm{C}$ (see Fig. 1 for ganoderic acids) are unique constituents of "Lingzhi". Incidentally, profiles in Ofodile et al. (2005) indicated interesting differences between species, in addition to the activities reported. TLC was applied for the differentiation of species and unique triterpene patterns were reported (Huie and Di, 2004). Samples could be grouped into 18, which were similar clusters to those by HPLC. Similarly, distinctive TLC patterns of triterpenes were obtained from basidiocarps of G. lucidum and G. tsugae. A rapid agar 
plug method of cultures and solvent extraction of basidiocarps of Ganoderma from oil palm were described in Miller et al. (1995). Some of the metabolites were analysed by mass spectrometry and did not appear to be lanostanoid compounds. Di et al. (2003) used high-performance TLC for the profiling of carbohydrates. This was the first time this approach had been used. Unique patterns were observed between $G$. applanatum and G. lucidum. The analyses of more strains and taxa are required generally (see Figs. 2 and 3).

Triterpenoid profiling for the chemotaxonomy of G. lucidum and related species has been demonstrated by HPLC. Also, the determination and comparison of production yields was obtained (Huie and Di, 2004). Samples could be divided into 18 groups based on characteristics of the HPLC pattern of triterpenoids, in good agreement with morphological examination (and TLC). Rapid and efficient characterization of "Lingzhi" was obtained. In addition,

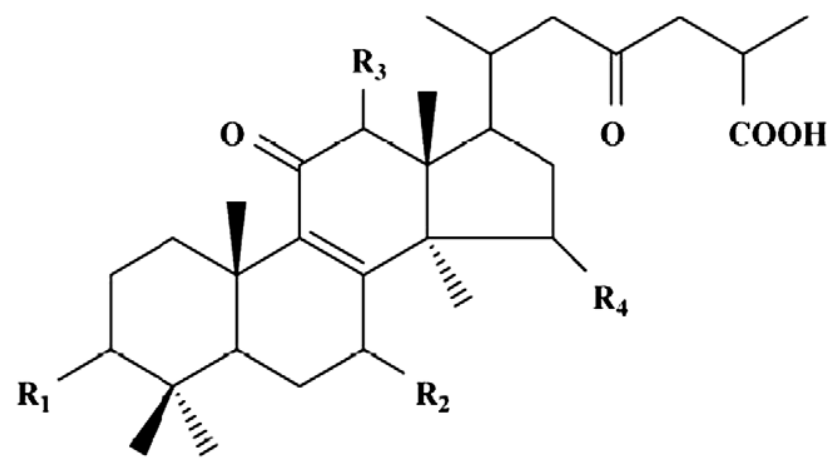

Ganoderic acid $\mathrm{C}_{2}(1): \mathrm{R}_{1}=\mathrm{R}_{2}=\beta-\mathrm{OH}, \mathrm{R}_{3}=\mathrm{H}, \mathrm{R}_{4}=\alpha-\mathrm{OH}$

Ganoderic acid $B(2): R_{1}=R_{2}=\beta-O H, R_{3}=H, R_{4}=O$

Ganoderic acid $\mathrm{AM}_{1}(3): \mathbf{R}_{1}=\beta-\mathrm{OH}, \mathbf{R}_{2}=\mathbf{R}_{\mathbf{4}}=\mathrm{O}, \mathrm{R}_{\mathbf{3}}=\mathrm{H}$

Fig. 2. Chemical structure of some ganoderic acids.
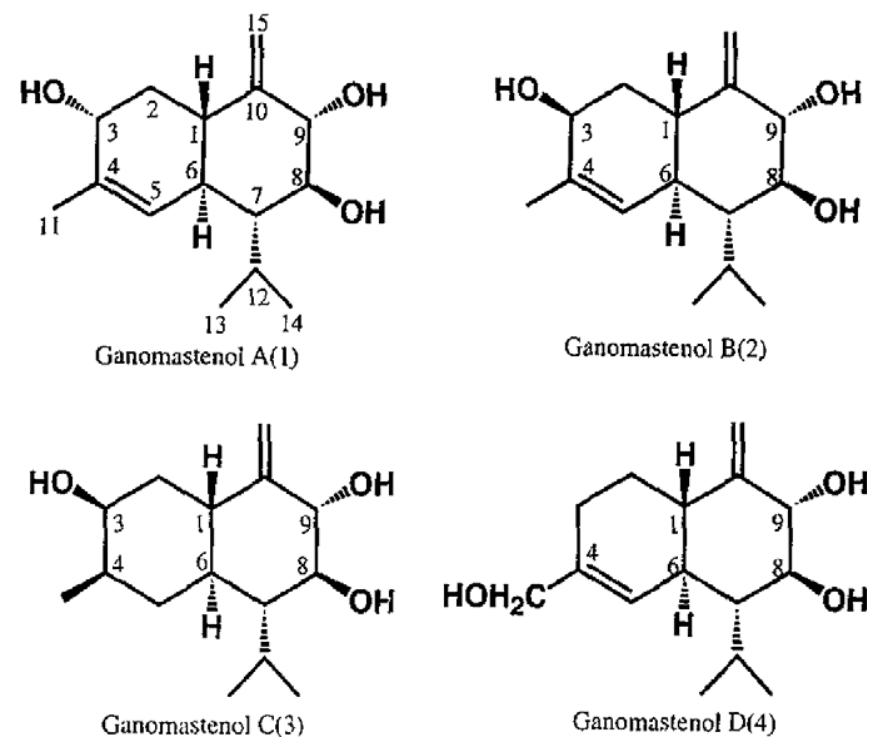

Fig. 3. Chemical structure of some ganomastenols. strains of G. tsugae and G. lucidum were analysed for triterpenoid of their basidiocarps. An HPLC procedure was employed for the isolation of oxygenated triterpenoids from crude extracts which has chemotaxonomic applications (Lin and Shiao, 1987). Strain specific profiles were obtained for G. lucidum (Nishitoba et al., 1986), and similar patterns were observed by Hirotani et al. (1993a). Chen et al. (1999) deduced some strains were similar and yet others different. The profiles provide useful chemotaxonomic data and activity/quality information.

Fourier transform infrared absorption and HPLC for the classification/identification of commercial $G$. lucidum and G. tsugae products into three different types (cultured mycelia, fruiting bodies and mixed mycelia/fruiting bodies) are also reported. Other workers have isolated nine triterpenoids from the basidiocarps of G. tsugae: ganoderic acids E, C5, C6, G and ganoderenic acid D (see Table 1) were analysed for the first time by HPLC. A method for determining ganoderic acid B in different parts of G. lucidum has been validated. The pilei (caps) were found to be the optimal source of ganoderic acid B, followed by the stipes (stems), and the spores were the poorest source. Similarly, the determination of ganoderic acid $\mathrm{A}$, ganoderic acid $\mathrm{C}$, ganoderic acid $\mathrm{D}$ and ganoderic acid $\mathrm{E}$ in cultured and wild G. lucidum was achieved, and this method was claimed to be highly suitable for the quality control of "herbal" formulations containing "Lingzhi" (Huie and Di, 2004). A validated method was reported for the simultaneous analysis of ganosporeric acid A, lucidenic acid A, ganoderic acids B and C from G. lucidum. Interestingly, it was found that the contents of four triterpenes in the fruiting bodies were higher than that in the spores, and the triterpene contents in the spores with a sporoderm-breaking rate of $85 \%$ were found to be higher than those obtained from spores having complete sporoderms. Another method was described for the quantitative analysis of the ganoderic alcohols and acids in the spores and five basidiocarps of G. lucidum collected from different countries. Six ganoderic alcohols (lucidumols $\mathrm{A}$ and $\mathrm{B}$, ganoderiols $\mathrm{A}$ and $\mathrm{F}$, ganodermanontriol A, ganodermanondiol) were well separated. Seven ganoderic acids also were well separated except for ganoderic acids $\mathrm{Cl}$ and $\mathrm{H}$ on the same column using $2 \%$ ethanol-acetonitrile (7:3) as the mobile phase. The results indicated that the total triterpene content of the spores was 5-20 times higher than that of the fruiting bodies (Huie and $\mathrm{Di}, 2004)$. In contrast, other researchers have shown that the spores were the poorest source of triterpenes. Miller et al. (1995) describe an HPLC method using gradient solvent elution and UV detection which was used for Ganoderma from oil palm, and it is desirable that the bioactivities of oil palm isolates are determined.

Wang et al. (2006) analysed various Ganoderma species for triterpenoids and the qualitative profiles of the species indicate utility for separating the taxa. However, both $G$. lucidum and $G$. sinense are the official species of Lingzhi recorded in the 2005 Chinese Pharmacopoeia and they were considered to have the same therapeutic effects. The 
Table 1

A composite table comparing some polysaccharides and terpenoids/steroids from Ganoderma spp. reported in the journal Phytochemistry from the 1970s to present

\begin{tabular}{|c|c|c|c|c|c|c|c|c|c|c|}
\hline \multirow{2}{*}{$\begin{array}{l}\text { Compounds } \\
\text { Polysaccharides }\end{array}$} & \multicolumn{10}{|c|}{ Ganoderma species } \\
\hline & lucidum & applanatum & lipsiense & carnosum & sugae & mastoporum & neo-japonicum & amboinense & Indonesian sp. & australe \\
\hline \multicolumn{11}{|l|}{ Heteroglucan } \\
\hline PL-1 & + & & & & & & & & & \\
\hline PL-2 & + & & & & & & & & & \\
\hline \multicolumn{11}{|l|}{ Homoglucan } \\
\hline PL-3 & + & & & & & & & & & \\
\hline \multicolumn{11}{|l|}{ Terpenoids and steroids } \\
\hline (24S)-24-methylcholesta-7,16-dien-3 $\beta$-ol & & + & & & & & & & & \\
\hline$(24 \xi)-24-m e t h y l-5 \alpha$-cholest-7-en-3 $\beta$-ol & & + & & & & & & & & \\
\hline (24S)-24-methyl-5 $\alpha$-cholest-7,16-dene-3 $\beta$-ol & & + & & & & & & & & \\
\hline 24-Methylcholesta-7,22-dien-3 $\beta$-ol & + & + & & & & & & & & \\
\hline 24-Methylcholesta-5,7,22-trien-3 $\beta$-ol ergosterol & + & + & & & & & & & & \\
\hline 24-Methylcholest-7-en-3 $\beta$-ol & + & + & & & & & & & & \\
\hline (24S)-24-methyl- $5 \alpha$-cholest-7-ene- $3 \beta$ ol (Ia) & & + & & & & & & & & \\
\hline Sesquiterpene (-)-7-hydroxycalamenene & & + & & & & & & & & \\
\hline Friedelin (terpene) & & + & & & & & & & & \\
\hline Alnusenone & & + & & & & & & & & \\
\hline Friedoolean-5-en-3one & & + & & & & & & & & \\
\hline Ergosta-5,7,22-triene-3 $\beta$-ol & & + & & & & & & & & \\
\hline Ergosterol & + & + & + & & & & & & & + \\
\hline Ergosta-7,22-diene-3-one & & + & & & & & & & & \\
\hline Ergosterol peroxide ${ }^{1}$ & & + & & & & & & & & \\
\hline Ergosterol peroxide & + & & & + & & & & & & \\
\hline Ergosta-7,22-diene-3 $\beta$-yl palmitate & + & & & & & & & & & \\
\hline 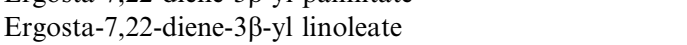 & + & & & & & & & & & \\
\hline 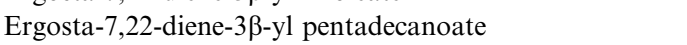 & + & & & & & & & & & \\
\hline Ergosta-7-diene-3 $\beta$-yl linoleate & + & & & & & & & & & \\
\hline Ergosta-7,22-dien-3 $\beta$-ol & & & + & + & + & & & & & \\
\hline Ergosta-7,22-dien-3-one & & & + & & & & & & & \\
\hline 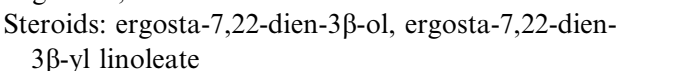 & & & & & & & & + & & \\
\hline Steroid: ergosta-7,22-dien-3 $\beta$-yl palmitate & & & & & & & & + & & \\
\hline Steroid: $2 \beta, 3 \alpha, 9 \alpha$-trihydroxyergosta-7,22-diene & & & & & & & & + & & \\
\hline Steroid: $5 \alpha, 8 \alpha$-epidioxyergosta- $6,9(11), 22$-trien-3 $\beta$-ol & & & & & & & & + & & \\
\hline Triterpenoid esters & & & & & & & & & & \\
\hline Ganoderic acid A, B, C1, H & + & & & & & & & & & \\
\hline Ganoderic acid N? & & & + & & & & & & & \\
\hline Ganoderic acid methyl ester & + & & + & & & & & & & \\
\hline Ganoderic derivatives & $\begin{array}{l}\text { Sekishi/Shishi } \\
\text { strains }+ \\
\text { Kokushi - }\end{array}$ & & & & & & & & & \\
\hline $\begin{array}{l}\text { Ganoderic acid } \mathrm{V}_{1}:(24 E)-3 \beta, 20 \xi \text {-dihydroxy-7,11,15- } \\
\text { trioxo-5 } \alpha \text {-lanosta-8,24-dien-26-oic acid }\end{array}$ & + Shishi strain & & & & & & & & & \\
\hline $\begin{array}{l}\text { Ganoderic acid } \mathrm{V}_{1}:(24 E)-3 \beta, 20 \xi \text {-dihydroxy-7,11,15- } \\
\text { trioxo-5 } \alpha \text {-lanosta-8,24-dien-26-oic acid }\end{array}$ & + Shishi strain & & & & & & & & & \\
\hline $\begin{array}{l}\text { Triterpenoids Ten ganoderic acid, ganoderenic acid and } \\
\text { lucidenic acid derivatives }\end{array}$ & + & & & & & & & & & \\
\hline
\end{tabular}


Polysaccharides
Triterpenoids, ganoderic acid T, ganoderic acid S,
ganoderic acid R, ganoderic acid P, ganoderic acid Q,

lucidum applumatum

lipsiense

carnosum

sugae

mastoporum

neo-japonicum

amboinense

Indonesian $\mathrm{sp}$

australe

ganoderic acid 0

7-O-methyl-ganoderic acid 0

Ganoderenic acid A

Ganoderenic acid D

Three linoleic acid steryl esters 3-5

Ganoderiols A, B, F

Ganodermanontriol

Cerevisterol

$3 \beta$ - $5 \alpha$-dihydroxy- $6 \beta$-methoxyergosta-7,22-diene

+ mycelium

Lanostane-type triterpene

26,27-Dihydroxylanosta-7,9(11),24-trien-3,16-dione

Oleic acid methyl ester

Glycerol trioleate

Known lanostanoids

$3 \beta$-hydroxy-5 $\alpha$-lanosta-8,24-dien-21-oic acid

3-Oxo-5 $\alpha$-lanosta-8,24-dien-21-oic acid

New lanostanoids

$3 \alpha$-acetoxy-5 $\alpha$-lanosta-8,24-dien-21-oic acid (tsugaric

acid A)

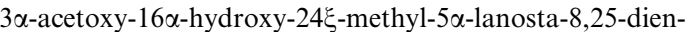

21-oic acid (tsugaric acid B)

Cadinene sesquiterpenes

Ganomastenols A-D cultured mycelia and broth

Polyoxygenated lanostanoid triterpenes

Applanoxidic acids E-H

+ mycelium
+
+
+
+
+
+

Drimane-type sesquiterpenoids: cryptoporic acid H, I

5'-deoxy-5'-methylsulphinyladenosine (both epimers)

Oxygenated triterpenes: lanosta-7,9(11),24-trien-3 $\alpha, 15 \alpha$ dihydroxy-26-oic acid

Polyhydroxyl steroid: $2 \beta$-methoxyl-3 $3 \alpha, 9 \alpha-$

dihydroxyergosta-7,22-diene

Lanostanoid: ganoderic acid $\mathrm{AM}_{1}, 3 \beta$-hydroxy-7,11,15,23-

tetraoxo-lanosta-8-en-26-oic acid

Lucidone A

Two homolanostanoid triterpene hydroxyacids

Carboxyacetylquercinic acid

Lanosta-7,9(11),24-trien-3 $\beta, 15 \alpha$-dihydroxy-26-oic-acid

Lanosta-7,9(11),24-trien-3 $\beta, 22 \beta$-diacetoxy-15 $\alpha$-hydroxy26-oic acid

Lanosta-7,9(11),24-trien-15 $\alpha, 22 \beta$-diacetoxy-3 $\beta$-hydroxy26-oic acid

Five new lanostanoid triterpenes

Ergosterol derivative: ergosta-4,7,22-triene-3,6-dione

$3 \beta, 7 \beta, 15 \alpha$-trihydroxy-11,23-dioxo-5 $\alpha$-lanost-8-en-26-oic

acid (ganoderic acid E)

\footnotetext{
+ mycelium

+ mycelium

+ mycelium

$+$

+ mycelium
}

+ (trop.

Indonesia)

+ mycelum 
average content of total triterpenoids in G. lucidum was 10 times higher than that in $G$. sinense, which indicated the therapeutic effects of these two species might be quite different. Therefore, they are recommended to be used as two different "herbal" medicines. Other obvious conclusions would be that the compounds are not responsible for the effects, or that the effects have not been scientifically proven. This represents a common problem with some of the data and interpretations reviewed herein. In general, there appears to be an assumption that the therapeutic effects attributed to the fungus have been proven.

Polysaccharides of "Lingzhi" and "related species" have been reported to be composed of a variety of monosaccharides, including glucose, galactose, mannose, arabinose, xylose, fucose, rhamnose, glucuronic acid and galacuronic acid and could be separated by paper chromatography (Huie and Di, 2004). The use of HPLC (or TLC) for carbohydrates is reported rarely. High performance size exclusion chromatography has been used for the quality control of "Siwei Lingzhi". However, the chemicals from Ganoderma have been described and this is considered in the following section.

\section{Chemical constituents}

Polysaccharides and triterpenes have been most thoroughly investigated from G. lucidum and related species. However, sterols, lectins and proteins have also been described. A list of the components which have been discussed in the journal Phytochemistry is provided in Table 1. This does not represent a chemotaxonomic treatment as certain taxa have been analysed much more than others. Nevertheless, some species produce the same compounds and strain variation is revealed.

\subsection{Triterpenes/triterpenoids}

Cole et al. (2003) list four sesqueterpene compounds from G. mastoporum: ganomastenol, ganomastenol B, ganomastenol C, and ganomastenol D (see Table 1). Cole and Schweikert (2003) include ergosterol; (24S)24-methyl$5 \alpha$-cholesta-7,16-dien-3 $\beta$-ol; (24S)24-methylcholesta-7,22dien-3-one (Ergosta-7,22-dien-3-one) as $\mathrm{C}_{28}$ sterols from G. applanatum. However, the names are also "equal to" four other Fomes species indicating a general systematic problem. An equivalent situation exists for the $\mathrm{C}_{30}$ sterols friedelin and alnusenone (friedoolean-5-en-3-one): These are listed as being from $G$. applanatum. Officinalic acid and senexdiolic acid (also $\mathrm{C}_{30} \mathrm{~s}$ ) are listed from $F$. officinalis and $F$. senex, respectively. From G. lucidum only are presented (a) 40 ganoderic acids, (b) 14 ganoderiols, (c) 5 ganolucidic acids, and (d) 15 lucidenic acids. It would be interesting to determine which other species (or genera) produce these compounds. Understandably, the authors put a disclaimer about the taxonomic veracity of the names they use in the volumes. 
Furthermore, Akihisa et al. (2005) describe (a) two triterpenoids: 20(21)-dehydrolucidenic acid $\mathrm{A}$ and methyl 20(21)-dehydrolucidenate A, and (b) five new 20-hydroxylucidenic acids: 20 -hydroxylucidenic acid $\mathrm{D}_{2}, 20$-hydroxylucidenic acid $F$, 20-hydroxylucidenic acid $\mathrm{E}_{2}, 20-$ hydroxylucidenic acid $\mathrm{N}$, and 20-hydroxylucidenic acid $\mathrm{P}$ isolated from the basidiocarps of G. ludicum. Shim et al. (2004) isolated four new lanostane-type triterpenes from the methanol extract of the fruiting bodies of G. applanatum. These are: (a) $3 \beta, 7 \beta, 20,23 \xi$-tetrahydroxy-11,15-dioxo-

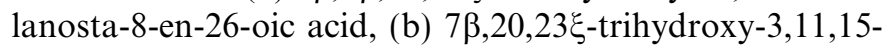

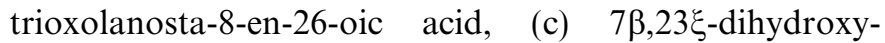
3,11,15-trioxolanosta-8,20E(22)-dien-26-oic acid, and (d) 7ß-hydroxy-3,11,15,23-tetraoxolanosta-8,20E(22)-dien-26oic acid methyl ester. The authors suggest that more of these classes of compounds will be detected in future studies. The free sterols of $G$. applanatum and G. lucidum has been determined to contain mainly (ergosterol) and 24methylcholesta-7,22-trien-3-ol. Also, the first isolation of 8,9-epoxyergosta-5,22-dien-3,15-diol from G. lucidum was reported (Huie and Di, 2004). So which biomedical activities have been described?

\section{Whole fungus/crude extracts bioactivities}

Ganoderma have been investigated as anti-tumour and antiviral agents and less so as anti-bacterial agents (Gao et al., 2003). Anti-bacterial activity has been observed against Gram-positive bacteria from the basidiocarp extracts of G. lucidum (Kim et al., 1993) and G. orgonense (Brian, 1951). Furthermore, Sudirman and Mujiyati (1997) observed that seven Indonesian Ganoderma species inhibited the growth of Bacillus subtilis. Yoon et al. (1994) investigated the additive effect on the activity of an aqueous extract of G. lucidum with four known antibiotics and observed that the anti-bacterial activity increased. There are relatively few studies on extracts from the liquid cultivated mycelium. Coletto and Mondino (1991) noted that methanolic extracts of the mycelia and culture extracts of G. recinaceum and G. lucidum inhibited B. subtilis. G. recinaceum also inhibited Staphylococcus aureus. Ethanolic extracts from $G$. lucidum mycelium demonstrated significant anti-inflammatory effects (Kendrick, 1985). Shieh et al. (2001) concluded that the hepatic and renal protective mechanism of G. lucidum might be because of its superoxide scavenging effect. In addition, Lin et al. (1995) observed that the greatest anti-hepatotoxic activity also exhibited the highest free radical scavenging properties. Low molecular weight aqueous fractions strongly inhibited multiplication of HIV-1 (Kim et al., 1997). The basidiocarps of G. lucidum lowered plasma cholesterol levels in rats (Kabir et al., 1988).

In terms of the very recent literature, it is noted from the company web site mentioned previously, that preparation from five Ganoderma "species" are, "known to fortify the immune system while exerting anti-inflammatory and anti-allergenic effects". These carry a footnote saying that the statements have not been evaluated by the US Food and Drug Administration. This is mentioned here as a blurring of scientific rigour which appears occasionally to be an issue when dealing with Ganoderma. We need to get away from this virtual-air-conditioned science and back to a situation where scientist actually collect and identify their own specimens (Korf, 2005).

To continue, the effects of G. lucidum on cancer cells was investigated (Sliva, 2006) and inhibition of proliferation and apoptosis was observed in leukemia, lymphoma, and myeloma cells. Moreover, the inhibition of acute myoloblastic leukemia cells was associated with cell cycle arrest and apoptosis, whereas the inhibition of lymphoma was mediated by the upregulation of expression. G. lucidum inhibits distinct signalling pathways in different cancer cells. Finally, standardized G. lucidum extracts containing $0.15 \%$ ganoderic acid C2 were used. However, it is uncertain if this amount of ganoderic acid could be responsible for the effect on haematopoietic cells. Finally, the composition and amount of biologically active triterpenes depend on the places of production, cultivation conditions, extraction procedures and the strains of G. lucidum.

Extracts of G. lucidum inhibited markedly intracellular signalling and invasive behaviour of cancer cells, whereas others did not. This complexity can also bring significant advantages. For example, certain components in the natural products can reduce the cytotoxicity of the whole product (and vice versa - my addition). Also, the interaction between different biologically active components can be responsible for their effects in vivo. Different compounds can modulate unrelated signalling and therefore, can possess synergistic effects (see Aydemir, 2002). Thus, triterpenes in G. lucidum suppress growth and invasive behaviour of cancer cells, whereas the polysaccharides stimulate the immune system resulting in the production of cytokines and activation of anti-cancer activities of immune cells (Sliva, 2006).

In summary, the organism inhibits (a) proliferation and invasive behaviour of breast and prostate cancer cells; (b) growth and induces apoptosis of breast and prostate cancer cells; (c) growth of hepatoma cells; and (d) secretion of vascular endothelial growth factor suppressing angiogenesis and transforming growth factor from prostate cancer cells. In addition, it induces apoptosis of colon cancer cells (Sliva, 2006). Stanley et al. (2005) demonstrated that $G$. lucidum induces apoptosis, inhibits cell proliferation, and suppresses cell migration of human prostate cancer cells. However, the molecular mechanism(s) has not been fully elucidated.

G. lucidum may have an immuno-modulating effect in patients with advanced colorectal cancer (Chen et al., 2006). Further studies are needed to explore the benefits and safety to cancer patients. In addition, there is further evidence of G. lucidum inhibiting prostate cancer cell proliferation (Johnston, 2005). Pero et al. (2005) report on a combination of mushroom extracts (Cordyceps sinensis, 
Grifola blazei, Gr. frondosa, Trametes versicolor and G. lucidum) into a formulation designed to optimise different modes of immunostimulatory action, and yet that would avoid metabolic anti-oxidant competition. Less than expected efficacious effects were obtained. However, despite this, the data were taken as strong evidence that the combination gave additive or synergistic effects to health. Furthermore, an extract from G. lucidum was screened by Müller et al. (2006) for anti-proliferative activity using a human cancer cell line. The results indicated that $G$. lucidum had a profound activity against leukemia, lymphoma and multiple myeloma cells and may be a novel adjunctive therapy for the treatment of haematologic malignancies. Kuo et al. (2006) obtained supportive evidence for the effect of dried mycelium of G. lucidum on the enhancement of innate immune response. Lin et al. (2006) investigated the effects of two G. tsugae supplement products and the results suggest that supplementation diets might alleviate bronchoalveolar inflammation via decreasing the infiltration of inflammatory cells and the secretion of inflammatory mediators into the lungs and airways. Overall, the results indicated a therapeutic application for G. tsugae in allergic asthma.

To continue, a methanol extract of G. lucidum demonstrated the strongest $5 \alpha$-reductase inhibitory activity among 19 edible and medicinal mushrooms (Noguchi et al., 2005). A clinical trial was conducted to evaluate the safety and efficacy of the extract in men with mild symptoms of bladder outlet obstruction and significant reductions in the problem were observed. The extract of
G. lucidum was well tolerated. Fujita et al. (2005) investigated the inhibitory effects of methanol extracts of 19 edible and medicinal mushrooms on $5 \alpha$-reductase activity (see also Noguchi et al., 2005). The extract of G. lucidum Fr. Krast showed the strongest inhibitory activity. The treatment of the fruit body of the fungus or the extract prepared from it inhibited significantly the testosterone-induced growth of the ventral prostate in castrated rats. These results showed that $G$. lucidum might be a useful ingredient for the treatment of benign prostatic hyperplasia. Presumable the extracts were similar to those reported by Mau et al. below.

G. tsugae was available in the form of mature and baby Ling chih (note different spelling and construction), mycelia and fermentation filtrate (Mau et al., 2005a). The term "baby" is of course unscientific. From methanolic extracts the mature and baby Ling chih demonstrated high anti-oxidant properties. Total phenols were the major naturally occurring anti-oxidant components found in all extracts and in the range of $24.0-35.6 \mathrm{mg} \mathrm{g}^{-1}$. Therefore phenols may not be the active component as the mycelium and filtrate were inactive. In hot water extracts from the same high anti-oxidant activities were again obtained (Mau et al., 2005b). At $20 \mathrm{mg} / \mathrm{ml}$, the scavenging abilities on hydroxyl radicals were in the descending order of Ling chih $>$ baby Ling chih $>$ mycelia $>$ filtrate. Again total phenols were the major naturally occurring anti-oxidant components found in hot water extracts and in the range of $40.86-42.34 \mathrm{mg} / \mathrm{g}$. From $\mathrm{EC}_{50}$ values obtained, fruit bodies of $G$. tsugae (Ling chih and baby Ling chih) were

Table 2

General compounds and effects of Ganoderma reported in the literature until 2004

\begin{tabular}{|c|c|c|}
\hline Compound & Effect & Reference \\
\hline Adenosine & Antiplatelet aggregation & Kawagishi et al. (1993), Shimizu et al. (1985) \\
\hline Lectins & Mitogenic & Ngai and Ng (2004) \\
\hline \multirow[t]{8}{*}{ Polysaccharides } & Antifibriotic & Park et al. (1997) \\
\hline & Antiherpetic & Eo et al. (1999a,b, 2000), Kim et al. (2000), Oh et al. (2000) \\
\hline & Anti-inflammatory & Ukai et al. (1983) \\
\hline & Hepatoprotective & Zhang et al. (2002) \\
\hline & Hypoglycaemic & Hikino et al. (1985, 1989), Hikino and Mizuno (1989), \\
\hline & & Tomoda et al. (1986), Zhang and Lin (2004) \\
\hline & Immuno-modulatory - anti-tumour & $\begin{array}{l}\text { Gao et al. (2000a,b), Li et al. (2000), Li and Zhang (2000), } \\
\text { Ooi et al. (2002), Sasaki et al. (1971), Sone et al. (1985) }\end{array}$ \\
\hline & $\begin{array}{l}\text { Miscellaneous (radiation protection, } \\
\text { DNA damage, anti-oxidant) }\end{array}$ & Kim and Kim (1999b), Lee et al. (2001) \\
\hline \multirow[t]{2}{*}{ Protein (“LZ-8”) } & Immunodulatory & van der Hem et al. (1995) \\
\hline & Immunosuppressive & van der Hem et al. (1995) \\
\hline \multirow[t]{11}{*}{ Terpenoids and related compounds } & Anti-bacterial & Smania et al. (1999) \\
\hline & "Anti-complement", & Min et al. (2001) \\
\hline & Anti-inflammatory & Kleinwächter et al. (2001) \\
\hline & Anti-oxidant & Zhu et al. (1999) \\
\hline & Antiplatelet aggregation & Shiao $(1992)$ \\
\hline & Antiviral & El-Mekkawy et al. (1998), Mothana et al. (2003) \\
\hline & Cytotoxicity & $\begin{array}{l}\text { Gao et al. (2002), Gonzalez et al. (2002), Kimura et al. (2002), } \\
\text { Lin et al. (1991), Su et al. (2000), Wu et al. (2001) }\end{array}$ \\
\hline & Enzyme inhibitors & Lee et al. (1998) \\
\hline & Hepatoprotective & Chen and Yu (1999), Kim et al. (1999) \\
\hline & Hypolipidemic (chloresterol inhibitors) & Komoda et al. (1989), Shiao (1992) \\
\hline & Hypotensive & Morigiwa et al. (1986) \\
\hline
\end{tabular}


"good" in anti-oxidant properties, except for the chelating ability on ferrous ions. It is clear that the methanol and aqueous extracts were similar and one wonders why two papers were required to reveal this.

Lu et al. (2004) detected the chemo-preventive effects of G. lucidum using a unique in vitro human urothelial cell (HUC) model consisting of HUC-PC and other cells. Ethanol and water extracts of basidiocarps and spores of the G. lucidum were used. Results indicated that ethanol extracts had a stronger growth inhibition effect than water extracts. At non-cytotoxic (see Table 2) concentrations $(40-80 \mu \mathrm{g} / \mathrm{ml})$, these extracts induced actin polymerization, which in turn inhibited carcinogen 4-aminobiphenyl induced migration in both cell lines. Again there may be similarity in chemical composition to the extracts mentioned previously. In conclusion, preclinical and clinical studies are necessary for the validation of this natural product in the prevention and/or therapy of cancer (Sliva, 2006) and other applications. Also, the effects of isolated compounds require to be tested further as discussed subsequently.

\section{Pure chemicals and biomedical applications}

Gao et al. (2003) reviewed the "antiviral value" of the genus Ganoderma, which provided the major biologically active constituents and their effect or mode of action. The anti-cancer effects of G. lucidum were associated with triterpenes, polysaccharides, (and)/or immuno-modulatory proteins, via inhibition of DNA polymerase, inhibition of post-translational modification of the Ras oncoprotein, or the stimulation of cytokine production (Sliva, 2006). Active components of the fungus have been discovered in (a) liquid cultivated mycelia (Gao et al., 2000b), (b) culture medium (Song et al., 1998; Tasaka et al., 1988a) and (c) the spores (Min et al., 2001). Basidiocarps are well known to contain active compounds. A list of the biological activities and broad chemical groupings is provided in Table 2.

\subsection{Triterpenoids and sterols}

Terpenoids are comprised of four groups: the (a) volatile mono- and sesquiterpenes (essential oils) (C10 and $\mathrm{C} 15)$, (b) less volatile diterpenes (C20), (c) involatile triterpenoids and sterols (C30), and (d) the carotenoid pigments (C40). Most investigations on Ganoderma concern the less volatile triterpenoid (triterpene) and sterol forms although there appears to be some confusion over names (see Lindequist, 1995). Increasingly other species to G. lucidum are now being investigated for triterpenoids and steroids. Kim and Kim (1999a) have summarised structural relationships in G. lucidum. The triterpene chemical structure is based on that of lanosterol, an important intermediate. Structural diversity is brought about by stereochemical rearrangements of this seminal compound. The physicochemical properties of over 130 lanostane-type triterpenoids have been described (Kim and Kim, 1999a) since ganodermic acid $\mathrm{A}$ and $\mathrm{B}$ were first described. The bitter components of "Lingzhi" are triterpenes/triterpenoids and have known pharmacological activities (Table 2; Huie and Di, 2004).

Interestingly, Nishitoba et al. (1986) suggested that triterpenes were specific to G. lucidum. However, they have been recorded subsequently in the following "species": $G$. colossum, G. applanatum, an unidentified Ganoderma sp., G. tsugae, G. concinna, G. tropicum and G. pfeifferi (Roberts, 2004). This indicates strongly that they are more closely related than first considered. The isolation of triterpenes from basidiocarps has been very well documented. Many have indicated biological activity as antitumour and antiviral agents: Spores are also sources. In fact, there are indications that spores have higher concentrations of ganoderic alcohols and acids than basidiocarps (Min et al., 1998). Cultivated mycelium has been reported to contain similar compounds (Lin et al., 2003).

Triterpenes are considered to be potential anti-cancer agents due to activity against growing tumours (Lin et al., 2003): they have direct cytotoxicity against tumour cells (Gonzalez et al., 2002) rather than enhancing the immune system as do polysaccharides. Basidiocarps of $G$. lucidum contain unique intensely-bitter compounds that may be related to activity (Mizuno, 1997). Furthermore, triterpenes inhibited HIV-1 protease (Min et al., 1998) and HIV-2 protease (El-Mekkawy et al., 1998). Hepatoprotective mechanisms of ganosporeric acid $\mathrm{A}$ from the spores of G. lucidum were observed by Chen and Yu (1999).

Also, triterpenoids from the basidiocarps of G. lucidum and G. applanatum, and malonate half-esters from the same Ganoderma species inhibitor tumour promotion (Chairul et al., 1991; Lin et al., 1991). However, and importantly, some esters showed toxicity at high concentrations (Chairul et al., 1990).

$\mathrm{Su}$ et al. (2000) examined the cytotoxic activity of lanostanoids from G. tsugae and found activity against three cancer cell lines. Lanostanoid and a sterol from G. tsugae caused cell death by apoptosis and suggested that it was the sterol that possessed the cell cycle inhibition activity (Gan et al., 1998a). Gonzalez et al. (2002) also observed apoptosis in human promyelocytic leukaemia HL-60 cells exposed to three lanostanoids isolated from $G$. concinna. In contrast, three triterpenoids from G. concinna inhibited calf and rat DNA polymerases implicated in DNA repair, recombination and DNA replication (Mizushina et al., 1999). Two terpenes, lucidenic acid O and lucidenic lactone, inhibited the HIV type 1 reverse transcriptase. Two cerebrosides from $G$. lucidum inhibited selectively the activities of replicative DNA polymerases in mammals (Mizushina et al., 1998) but had little effect on other polymerases, transferases, HIV reverse transcriptase, RNA polymerase, deoxyribonuclease I and ATPase. Morigiwa et al. (1986) observed that a methanol extract from the fruiting body of G. lucidum inhibited angiotensin-converting enzyme involved in the control of hypertension. The extract contained ten lanostane triterpenes, of which eight exhibited 
activity. Furthermore, ganodermic acid S from G. lucidum induced platelet aggregation by stimulating the hydrolysis of phosphatidylinositol 4,5-bisphosphate (Shiao, 1992). From these, and the more recent work reported below, it is known now that triterpenes possess bioactivities, such as anti-oxidation, hepatoprotection, anti-allergy, antihypertension, cholesterol reduction, and inhibiting platelet aggregation. The effects are from inhibition of enzymes such as galactosidase, angiotension converting enzyme, cholesterol synthase, etc. (Huie and Di, 2004).

Hajjaj et al. (2005) report the isolation and identification of the 26-oxygenosterols ganoderol A, ganoderol B, ganoderal $\mathrm{A}$, and ganoderic acid $\mathrm{Y}$ and they determined that the point of inhibition of cholesterol synthesis is between lanosterol and lathosterol. Interestingly, the 26-oxygenosterols could lead to novel therapeutic agents that lower blood cholesterol. Timo et al. (2005) isolated four sterols and 10 triterpenes from the fruiting bodies of G. pfeifferi, including the three new triterpenes: lucialdehyde $\mathrm{D}$, ganoderone $\mathrm{A}$, and ganoderone $\mathrm{C}$. Ganoderone A, lucialdehyde $\mathrm{B}$, (and ergosta-7,22-dien-3 $\beta$-ol) were found to exhibit potent inhibitory activity against herpes simplex virus. Very significant activity was established. Lanostanoid triterpenes isolated from $G$. amboinense inhibited (a) the growth of numerous cancer cell lines, and (b) the activities of topoisomerases I and II $\alpha$ ( $\mathrm{Li}$ et al., 2005). One of the most potent triterpene was ganoderic acid X (GAX). The ability of GAX to inhibit topoisomerases and to sensitize the cancer cells toward apoptosis fulfils the feature of a potential anti-cancer drug. Liu et al. (in press) state that the ethanol extract of G. lucidum demonstrated inhibitory activity on both isozymes of $5 \alpha$-reductase (see previously) and suppression effects of ventral prostate growth. Analysis suggested that the active principles in vivo were triterpenoids. These results indicate that the triterpenoids fraction of G. lucidum "might" be a useful ingredient in the treatment of benign prostatic hyperplasia. As mentioned previously, G. lucidum extracts containing $0.15 \%$ ganoderic acid $\mathrm{C} 2$ were used in demonstrating anti-cancer effects. However, it is uncertain if this amount of ganoderic acid could be responsible for the effect. In addition, different compounds can modulate unrelated signalling and therefore, can possess synergistic effect. The differing effects of triterpenes and polysaccharides are again noted.

In summary, recent research has demonstrated that: (1) a triterpene fraction from the mycelia of G. lucidum inhibited growth of human hepatoma cells, (2) the anti-oxidative activities of G. lucidum extracts were examined and the triterpene fraction (ganoderic acids A, B, C and D, lucidenic acid $\mathrm{B}$ and ganodermanotriol) exhibited the highest effect by testing the ingredients against pyrogallol induced oxidation on erythrocyte membrane and $\mathrm{Fe}(\mathrm{II})$-ascorbic acid induced lipid peroxidation in liver mitochondria, and (3) triterpenes isolated from the spores of G. lucidum, such as ganoderic acid, luciumol B, ganodermanodiol, ganodermanontriol and ganolucidic acid, showed significant antiHIV-1 protease activity.
Sterols are related closely to triterpenoids and are found in Ganoderma. The basidiocarps and mycelium and have potent cytotoxic activity. Ergosterolperoxide, from G. lucidum enhances the inhibitory effect of linoleic acid on mammalian DNA polymerase (Mizushina et al., 1998). The effect of Ganoderma total sterol (GS) and its main components $\left(\mathrm{GS}_{1}\right)$ on rat cortical neuronal cultures exposed to hypoxia/reoxygenation $(\mathrm{H} / \mathrm{R}$ ) was studied in vitro (Zhao et al., 2005) and the results suggest that GS might be useful in treating $\mathrm{H} / \mathrm{R}$-induced oxidative stress and inflammatory response. In addition, pre-treatment with $\mathrm{GS}_{1}$ significantly attenuated the decline of neuron viability and the formation of reactive oxygen species.

Anti-bacterial effects include those from steroidal compounds from the basiciocarps of $G$. applanatum, which were found to have broad spectrum activities and bactericidal effects (Smania et al., 1999). Ganomycins A and B, from G. pfeifferi exhibited anti-bacterial activity against Gram-negative and Gram-positive bacteria (Mothana et al., 2000). Sterols (Komoda et al., 1989) and oxygenated triterpenes (Shiao, 1992) have been shown to inhibit cholesterol synthesis in vitro.

\subsection{Polysaccharides}

Polysaccharides represent a structurally diverse class of biological macromolecules with a wide-range of physicochemical properties. The major bioactive Ganoderma polysaccharides species are $\beta-1-3$ and $\beta-1-6-\mathrm{D}$ glucans. The structure is $\beta-1-3$ D-glucopyronan with $1-15$ units of $\beta-1$ 6 monoglucosyl side chains.

Alternative anti-tumour compounds are glycoproteins (polysaccharides and proteins), heteropolysaccharides and ganoderans A, B and C (Lindequist, 1995). They have high molecular weights as a common feature which tends to increase water solubilities and result in more effective anti-tumour activity. However, some water insoluble polysaccharides also possess anti-tumour activity (Wang et al., 1993) and polysaccharide branching affects activity. Scientific investigations concerning the anti-tumour and immuno-modulating activities of G. lucidum were reported as early as in 1957 and, more recently, extensive studies on the anti-tumour ingredient(s), especially polysaccharides and protein/peptide bound polysaccharides, have been carried out. For example, several glucans that were isolated in the early 1980s from water and alkali extracts were found to be bioactive.

Bioactive polysaccharides have been isolated from the basidiocarps (Bao et al., 2002; Zhang and Lin, 2004) and from the mycelial biomass cultivated in liquid culture (Kim et al., 1993). Few have been isolated from the culture medium (Kim et al., 2003). Importantly, the water soluble polysaccharides of G. lucidum inhibited strongly the growth of Sarcoma 180 solid-type tumour, with an inhibition ratio of greater than $95 \%$. Most of the anti-tumour glucans were reported to contain a branched glucan core and an average molecular weight of 1,050,000 Da. Polysaccharides are 
believed to exert anti-tumour activities through an enhancement of host-mediated immunity rather than a direct cytotoxicity to the tumour cells. It should be noted that the amount of bioactive water-insoluble polysaccharides was found to be higher than that of water-soluble polysaccharides. More than 200 polysaccharides have been isolated from the fruiting bodies, spores, mycelia and cultivation broth of "Lingzhi" (Huie and Di, 2004).

In addition, polysaccharides from $G$. lucidum demonstrated activity (Kim et al., 1999; Zhang et al., 2002). Similar fractions from $G$. lucidum exhibited activity against HSV-1 and HSV-2 (Eo et al., 1999b, 2000; Kim et al., 2000; Oh et al., 2000). Unsurprisingly, high concentrations can be immunosuppressive and so it would be important to use safe concentrations for any proposed treatment.

Fractions from $G$. lucidum have been shown to inhibit tumour growth through activation of host-mediated immune responses by stimulating the production of inducing cytokines (or cytotoxic $\mathrm{T}$ lymphocytes) from mononuclear leukocytes (Lieu et al., 1992) and promoting the production of interleukin 2 (Lei and Lin, 1992; Ooi et al., 2002). The activity and mechanism of these polysaccharides was a major area of research at that time. It has also been observed that the host mediated anti-tumour effect is increased by the attachment of polyol groups to glucans (Sone et al., 1985). Anti-tumour activity against transplanted Sarcoma 180 in mice has been exhibited by the $\beta$-D-glucan polysaccharides from the basidiocarps of G. applanatum (Sasaki et al., 1971), G. lucidum (Sone et al., 1985 ) and the culture fluid of G. lucidum (Sone et al., 1985). Ooi et al. (2002) also observed the suppression of growth of Sarcoma 180 solid tumour in mice and a marked increase in the expression levels of immuno-modulatory cytokines in the presence of a hot-water-extracted G. lucidum polysaccharide. In contrast, there was no cytotoxic effect observed for a water-insoluble glucan from $G$. japonicum (Ukai et al., 1983) or for the mycelial extract from G. lucidum on oral tumour cells in vitro (Chen et al., 1991).

Six water-soluble polysaccharides were extracted sequentially from the mycelium of G. tsugae (Peng et al., 2005). They were heteropolysaccharide-protein complexes. GTM3 and GTM4 contained $(1 \rightarrow 3)-\beta$-D-glucans and $(1 \rightarrow 4)$ - $\alpha$-D-glucans, while GTM5 and GTM6 were mainly a $(1 \rightarrow 6)$-branched $(1 \rightarrow 3)$ - $\beta$-D-glucan. With the progress of isolation, the content of a fraction decreased from $90.2 \%$ to $57.1 \%$, and accompanied with enhanced antitumour activity. The polysaccharides GTM1, GTM2 and GTM3 had significantly higher anti-tumour activity against solid tumour Sarcoma 180 with an inhibition ratio higher than $50 \%$. The results suggested that the effects on the improvement of anti-tumour activities of polysaccharides "could not be negligible". Polysaccharides have been shown to enhance the activity of DNA polymerases (Lei and Lin, 1993). These authors observed the activity of DNA polymerase to increase in the splenocytes of mice, after they had administered intraperitoneally Ganoderma polysaccharides (GL-B).
Zhang and Lin (2004) and Hikino et al. (1985) observed that polysaccharides from the basidiocarps of G. lucidum possessed a hypoglycaemic effect in mice. However, studies by Tomoda et al. (1986) found that they were not glycans but peptidoglycans. An unusual report is available on a chitin membrane used as a wound dressing known as "sacchachitin" and developed from the residue of the fruiting body of G. tsugae (Su and Hsu, 1995).

In the most recent reports, Chen et al. (2006) present results indicating that $G$. lucidum may have potential immuno-modulating effect in patients with advanced colorectal cancer. More recent research into polysaccharides includes:

(1) Water soluble polysaccharides extracted from G. lucidum were effective in preventing DNA from strand breakage indicating the anti-tumour and immunomodulating activities of "Lingzhi" are strongly related to its anti-oxidative property.

(2) The anti-oxidant property of Ganoderma polysaccharide peptide decreased the oxidation of low density lipoprotein and exhibited anti-oxidant effect by scavenging reactive oxygen species in mice.

(3) A proteoglycan having a carbohydrate/protein ratio of 11.5 to 1 - isolated from G. lucidum, was found to stimulate the proliferation of mouse spleen lymphocytes, resulting in a three to fourfold increase in the (a) percentage of B cells, (b) secretion of immunoglobulin, (c) production of interleukin 2 and (d) expression of protein kinase.

(4) It was found that the polysaccharide extracts from the mycelium of G. lucidum exhibited anti-tumour effects against fibrosarcoma in male and female mice and inhibited the metastasis of a tumour to the lung. The bioactive polysaccharides could stimulate blood mononuclear cells to increase cytokines, tumour necrosis factor, interferon and interleukin production, and the lifespan of tumour-implanted mice was found to increase significantly due to the administration of GLP.

(5) Two protein bound polysaccharides, a neutral protein bound polysaccharide (NPBP) and an acidic protein bound polysaccharide (APBP), were isolated from water soluble substances of G. lucidum APBP was found to be more potent than NPBP as an antiviral agent against herpes simplex viruses (HSV). The antiviral activity of APBP appeared to be related to its binding with HSV-specific glycoprotein at the cell membrane (Huie and Di, 2004). G. lucidum polysaccharides (Gl-PS) have shown a variety of immune modulating effects. Results confirmed that Gl-PS was a promising biological response modifier and immune potentiator (Zhu and Lin, 2006).

The extraction procedures for polysaccharides involve standard methodology (see Huie and Di, 2004). However, the extraction of water insoluble polysaccharides from 
"Lingzhi" can be carried out by a cellulase hydrolysis reaction. This method is based on the attack of the enzyme on the polysaccharide substrates, composed of cellulose and lignin. However, lignin in the fungal preparation is very surprising and is probably a false assumption. This may have arisen from referring to the fungi as herbs as they may contain lignin. For information, it has been reported that enzyme hydrolysis reaction can be enhanced by ultrasonic waves.

\subsection{Proteins, peptides and amino acids}

Bioactive proteins have been isolated from various "Lingzhi" species and characterized by chromatographic/ electrophoretic techniques. For example, a new immunomodulatory protein, known as Ling Zhi-8 (LZ-8), was isolated from the mycelia of G. lucidum. LZ-8 is a polypeptide consisting of 110 amino acid residues with an acetylated amino terminus and has a molecular mass of $12 \mathrm{kDa}$ (Tanaka et al., 1989). Mitogenic activity and also has been reported (e.g. van der Hem et al., 1995).

Ngai and $\mathrm{Ng}$ (2004) isolated a lectin from G. capense that exhibited potent mitogenic activity toward mouse splenocytes and anti-proliferative activity toward leukaemia cells and hepatoma cells in vitro. The lectin exhibited more potent mitogenic activity than that of concanavalin A. It was found that three kinds of bioactive proteins from the fruiting body and spores of "Lingzhi" showed obvious mitogenic activity. Proteins in the form of enzymes have also been isolated and characterized by various types of column chromatography as well as electrophoretic techniques. For example, DEAE-Sephadex column (gel filtration) and Con A-Sepharose (affinity chromatography) were employed for the purification of galactosidase from the fruiting body of G. lucidum. In addition, a variety of amino acids have been found in Lingzhi. Oxidative stress has been linked with the pathogenesis of many human diseases including cancer, aging, and atherosclerosis (Sun et al., 2004). Their study investigated the potent anti-oxidant activities of peptides isolated from G. lucidum. Polysaccharides, polysaccharide-peptide complex (and phenolic components) of G. lucidum have been proposed to be responsible for this anti-oxidant effect. However, research has shown that the G. lucidum peptide is the major anti-oxidant component. In another investigation of $G$. lucidum polysaccharide peptide (Gl-PP) demonstrated some effects as anti-tumours compounds in mice and potential anti-angiogenesis (Cao and Lin, 2006). They elucidated the possible mechanism of G1-PP action on antiangiogenesis of tumours. Inducing cell apoptosis by GlPP might be the mechanism of inhibiting proliferation. Human lung carcinoma cells when exposed to high dose of Gl-PP in hypoxia for $18 \mathrm{~h}$ resulted in a decrease in an important chemical indicator of cancer. Taken together, these findings support the hypothesis that the key attribute of the anti-angiogenic potential of Gl-PP is that it may directly inhibit vascular endothelial cell proliferation or indirectly decrease growth factor expression of tumour cells.

Wang and $\mathrm{Ng}$ (2006) isolated a $15-\mathrm{kDa}$ antifungal protein, designated ganodermin, from G. lucidum. Ganodermin inhibited the mycelial growth of Botrytis cinerea, Fusarium oxysporum and Physalospora piricola. However, it was devoid of haemagglutinating, deoxyribonuclease, ribonuclease and protease inhibitory activities.

\subsection{Nucleosides, nucleotides and RNAs}

$\mathrm{Yu}$ and Zhai in an obscure journal (see Huie and Di, 2004) were the first to report the isolation of adenine, adenosine, uracil and uridine from the mycelia of a Ganoderma species, G. capense. Among these, nucleosides, uridine and uracil were found to be capable of lowering the serum aldolase level of mice suffering from experimental myotonia. Adenosine has also been shown to inhibit platelet aggregation (Shimizu et al., 1985). In contrast, Gau et al. (1990) found that the administration of crude Ganoderma extracts, known to have a high content of adenosine, had no effect on platelet aggregation in haemophiliac patients who were HIV positive. An epimer of 5'-deoxy-5'-methylsulphinyladenosine was found to inhibit platelet aggregation in vitro (Kawagishi et al., 1993). However, why these compounds should be different in any way than those from other sources is not clear (to me).

\subsection{Alkaloids, vitamins, essential minerals, flavours, and fatty acids}

The compounds cyclooctasulfur (Tasaka et al., 1988b) and oleic acid (Tasaka et al., 1988a), isolated from the culture broth of G. lucidum, were both found to inhibit histamine release which is an important activity for treatment of inflammation, allergies, and anaphtlactic shock. The alkaloids, choline and betaine were isolated from the spores of G. lucidum. Furthermore, two novel pyrrole alkaloids (ganoine and ganodine) and a novel purine alkaloid (ganoderpurine) were discovered from the mycelia of $G$. capense. Vitamins (including $\beta$-carotene) and essential elements have been isolated from various "Lingzhi" "species". Aroma compounds were detected from G. applanatum which may have novel biotechnological applications. Over 120 volatile flavour compounds, mostly alcohols, aldehydes, ketones, esters, and phenols, have been identified (Huie and Di, 2004). Finally, very-long-chain fatty acids with more than 23 carbon atoms have been reported in G. applanatum at trace levels (1-2\%).

\section{Toxicity}

It is obvious that this issue has received little attention in the literature, despite it being crucial for the success of any proposed medical treatments. This may reflect a certain 
lack of balance in reporting only the potential benefits. However, indications of toxicity are provided in Table 2.

\section{Conclusions}

The first thing to say is that the activity data on isolated compounds mentioned herein is very convincing. This review summarised important areas of investigation being performed on Ganoderma species around the world, with particular emphasis on chemicals of biomedical relevance. There is abundant evidence that these are effective, and more clinical trials are now in order. Searching for other secondary metabolites from Ganoderma may prove fruitful especially if the taxonomy was usefully revised.

However, unlike "Western medicine" in which therapeutic effects usually derive from a single chemical substance within the drugs, the pharmacologically activities of "herbal" medicines invariably arise from a mixture of "active" ingredients within the materials. In fact, in many cases, the biological activities of the active components administrated or consumed alone were found to be lower than those obtained from the original mixture of active ingredients present in herbs, such as "Lingzhi". Thus, the combined, synergistic effects of a mixture of active components that are present in "Lingzhi" on biological activities need to be thoroughly assessed. A factor which is not considered by those who appear to advocate using Ganoderma is the possibility of toxic components in the fungus and preparations, and more work is required in this area. Some combinations of compounds are more toxic than the individual parts while others "potentiate" usually non-toxic compounds. This is why a good chemotaxonomy is required of the genus and employing the bioactive components for this purpose. It is clear that many issues are raised of a systematic nature - not least as they relate to finding fungi with active but not toxic ingredients. Crucially, we need to know what the nonLatinised names actually represent - past and present.

In the search for active compounds from Ganoderma species, the majority of research has been performed on extracts from the fruiting body and there have been fewer studies on extracts from the liquid cultivated mycelium. It appears that there are a number of biologically active compounds to be found in the mycelium and the benefits of liquid cultivation over solid cultivation include: the ability to manipulate the cultivation medium to optimise mycelial growth; a shorter cultivation time; and less contamination. In fact, the reason that some of the Ganoderma preparations are not yet available as medicines may be from difficulties relating to mass production (Smith et al., 2002).

\section{Acknowledgement}

R.R.M. Paterson was supported by the Grant FRH/ BPD/14923/2004 from Fundação para a Ciência e Tecnologia, Portugal.

\section{References}

Akihisa, T., Tagata, M., Ukiya, M., Tokuda, H., Suzuki, T., Kimura, Y., 2005. Oxygenated lanostane-type triterpenoids from the fungus Ganoderma lucidum. J. Nat. Prod. 68, 559-563.

Aydemir, G., 2002. Research on nutrition and cancer: the importance of the standardized dietary assessments. Asian Pacific J. Cancer Prev. 3, $177-180$

Bao, X.-F., Wang, X.-S., Dong, Q., Fang, J.-N., Li, X.-Y., 2002. Structural features of immunologically active polysaccharides from Ganoderma lucidum. Phytochemistry 59, 175-181.

Brian, P.W., 1951. Antibiotics produced by mushrooms. Bot. Rev. 17, 357-430.

Cao, Q., Lin, Z., 2006. Ganoderma lucidum polysaccharides peptide inhibits the growth of vascular endothelial cell and the induction of VEGF in human lung cancer cell. Life Sci. 78, 1457-1463.

Chairul, T.T., Hayashi, Y., Nishizawa, M., Tokuda, H., Chairul, S.M., Hayashi, Y., 1991. Applanoxidic acids A, B, C and D, biologically active tetracyclic triterpenes from Ganoderma applanatum. Phytochemistry $30,4105-4109$.

Chairul, T.T., Nishizawa, M., Shiro, M., Tokuda, H., Hayashi, Y., 1990. Malonate half-esters of homolanostanoid from an Asian Ganoderma fungus. Phytochemistry 29, 923-928.

Chen, D.H., Shiou, W.Y., Wang, K.C., Huang, S.Y., Shie, Y.T., Tsai, C.M., Shie, J.F., Chen, K.D., 1999. Chemotaxonomy of triterpenoid pattern of HPLC of Ganoderma lucidum and Ganoderma tsugae. J. Chin. Chem. Soc. 46, 47-51.

Chen, R.Y., Yu, D.Q., 1999. Studies on the triterpenoid constituents of the spores of Ganoderma lucidum (Curt.:Fr.) P. Karst. (aphyllophoromycetideae). Int. J. Med. Mush. 1, 147-152.

Chen, T.W., Wong, Y.K., Lee, S.S., 1991. In vitro cytotoxicity of Ganoderma lucidum on oral cancer cells. Zhonghua Yi Xue Za Zhi (Taipei) 48, 54-58.

Chen, X., Hi, Z., Yang, X.-X., Huang, M., Gao, Y., Tang, W., Chan, S.Y., et al., 2006. Monitoring of immune responses to a herbal immuno-modulator in patients with advanced colorectal cancer. Int. Immunopharmacol. 6, 499-508.

Cole, R.J., Schweikert, M.A., 2003. Handbook of Fungal Secondary Metabolites, vol. 2. Academic Press, California.

Cole, R.J., Jarvis, B.B., Schweikert, M.A., 2003. Handbook of Fungal Secondary Metabolites, vol. 3. Academic Press, California.

Coletto, B.M.A., Mondino, P., 1991. Antibiotic activity in Basidiomycetes: V. Antibiotic activity of mycelia and cultural filtrates. Allionia (Turin) 30, 61-64.

Di, X., Chan, K.K.C., Leung, H.W., Huie, C.W., 2003. Fingerprint profiling of acid hydrolyzates of polysaccharides extracted from the fruiting bodies and spores of Lingzhi by high-performance thin-layer chromatography. J. Chromatogr. A 1018, 85-95.

Domínguez, X.A., Butruille, D., Zamudio, A., Reyes, C.G., Castillo, J.T., 1972. Ergosterol et L-mannitol dans des champignons parasites. Phytochemistry 11, 2616.

El-Mekkawy, S., Meselhy, M.R., Nakamura, N., Tezuka, Y., Hattori, M., Kakiuchi, N., Shimotohno, K., Kawahata, T., Otake, T., 1998. AntiHIV-1 and anti-HIV-1-protease substances from Ganoderma lucidum. Phytochemistry 49, 1651-1657.

Eo, S.K., Kim, Y.S., Lee, C.K., Han, S.S., 1999a. Antiherpetic activities of various protein bound polysaccharides isolated from Ganoderma lucidum. J. Ethnopharmacol. 68, 175-181.

Eo, S.K., Kim, Y.S., Lee, C.K., Han, S.S., 1999b. Antiviral activities of various water and methanol soluble substances isolated from Ganoderma lucidum. J. Ethnopharmacol. 68, 129-136.

Eo, S.K., Kim, Y.S., Lee, C.K., Han, S.S., 2000. Possible mode of antiviral activity of acidic protein bound polysaccharide isolated from Ganoderma lucidum on herpes simplex viruses. J. Ethnopharmacol. 72, 475-481.

Fujita, R., Liu, J., Shimizu, K., Konishi, F., Noda, K., Kumamoto, S., Ueda, C., Tajiri, H., Kaneko, S., Suimi, Y., Kondo, R., 2005. Anti- 
androgenic activities of Ganoderma lucidum. J. Ethnopharmacol. 31, $107-112$.

Gan, K.H., Fann, Y.F., Hsu, S.H., Kuo, K.W., Lin, C.N., 1998a. Mediation of the cytotoxicity of lanostanoids and steroids of Ganoderma tsugae through apoptosis and cell cycle. J. Nat. Prod. 61, 485487.

Gao, X.X., Fei, X.F., Wang, B.X., Zhang, J., Gong, Y.J., Minami, M., Nagata, T., Ikejima, T., 2000a. Effects of polysaccharides (FI0-b) from mycelium of Ganoderma tsugae on proinflammatory cytokine production by THP-1 cells and human PBMC (I). Acta Pharmacol. Sin. 21, $1179-1185$.

Gao, J.J., Min, B.S., Ahn, E.M., Nakamura, N., Lee, H.K., Hattori, M., 2002. New triterpene aldehydes, lucialdehydes A-C, from Ganoderma lucidum and their cytotoxicity against murine and human tumor cells. Chem. Pharm. Bull. (Tokyo) 50, 837-840.

Gao, X.X., Wang, B.X., Fei, X.F., Zhang, J., Gong, Y.J., Minami, M., Nagata, T., Ikejima, T., 2000b. Effects of polysaccharides (FI0-c) from mycelium of Ganoderma tsugae on proinflammatory cytokine production by THP-1 cells and human PBMC (II). Acta Pharmacol. Sin. 21, 1186-1192.

Gao, Y., Zhou, S., Huang, M., Xu, A., 2003. Antibacterial and antiviral value of the genus Ganoderma $\mathrm{P}$. Karst. species (aphyllophoromycetideae): a review. Int. J. Med. Mush. 5, 235-246.

Gau, J.P., Lin, C.K., Lee, S.S., Wang, S.R., 1990. The lack of antiplatelet effect of crude extracts from Ganoderma lucidum on HIV-positive hemophiliacs. Am. J. Chin. Med. 18, 175-179.

Gonzalez, A.G., Leon, F., Rivera, A., Padron, J.I., Gonzalez-Plata, J., Zuluaga, J.C., Quintana, J., Estevez, F., Bermejo, J., 2002. New lanostanoids from the fungus Ganoderma concinna. J. Nat. Prod. 65, 417-421.

Hajjaj, H., Macé, C., Roberts, M., Niederberger, P., Fay, L.B., 2005. Effect of 26-oxygenosterols from Ganoderma lucidum and their activity as cholesterol synthesis inhibitors. Appl. Environ. Microbiol. 71, 36533658 .

Hikino, H., Ishiyama, M., Suzuki, Y., Konno, C., 1989. Mechanisms of hypoglycemic activity of ganoderan B: a glycan of Ganoderma lucidum fruit bodies. Planta Med. 55, 423-428.

Hikino, H., Konno, C., Mirin, Y., Hayashi, T., 1985. Isolation and hypoglycaemic activity of ganoderans A and B, glycans of Ganoderma lucidum fruit bodies. Planta Med. 51, 339-340.

Hikino, H., Mizuno, T., 1989. Hypoglycemic actions of some heteroglycans of Ganoderma lucidum fruit bodies. Planta Med. 55, 385.

Hirotani, M., Furuya, T., Shiro, M., 1991. Cryptoporic acids H and I, drimane sesquiterpenes from Ganoderma neo-japonicum and Cryptoporus volvatus. Phytochemistry 30, 1555-1559.

Hirotani, M., Ino, C., Hatano, A., Takayanagi, H., Furuya, T., 1995. Ganomastenols A, B, C and D, cadinene sesquiterpenes, from Ganoderma mastoporum. Phytochemistry 40, 161-165.

Hirotani, M., Ino, C., Hirotani, T.F.M., Ino, C., Furuya, T., 1993a. Comparative study on the strain-specific triterpenoid components of Ganoderma lucidum. Phytochemistry 33, 379-382.

Huie, C.W., Di, X., 2004. Chromatographic and electrophoretic methods for Lingzhi pharmacologically active components. J. Chromatogr. B $812,241-257$.

Jain, A.C., Gupta, S.K., 1984. The isolation of lanosta-7,9(11),24-trien33,21-diol from the fungus Ganoderma australe. Phytochemistry 23, 686-687.

Johnston, N., 2005. Medicinal mushroom cuts off prostate cancer cells' blood supply. Drug Discov. Today 10, 23-24.

Kabir, Y., Kimura, S., Tamura, T., 1988. Dietary effect of Ganoderma lucidum mushroom on blood pressure and lipid levels in spontaneously hypertensive rats (SHR). J. Nutr. Sci. Vitaminol. (Tokyo) 34, 433-438.

Kac, D., Barbieri, G., Falco, M.R., Seldes, A.M., Gros, E.G., 1984. The major sterols from three species of polyporaceae. Phytochemistry 23, 2686-2687.

Kawagishi, H., Fukuhara, F., Sazuka, M., Kawashima, A., Mitsubori, T., Tomita, T., 1993. 5'-Deoxy-5'-methylsulphinyladenosine, a platelet aggregation inhibitor from Ganoderma lucidum. Phytochemistry 32, 239-241.

Kawagishi, H., Mitsunaga, S.-I., Yamawaki, M., Ido, M., Shimada, A., Kinoshita, T., Murata, T., Usui, T., Kimura, A., Chiba, S., 1997. A lectin from mycelia of the fungus Ganoderma lucidum. Phytochemistry 44, 7-10.

Keller, A.-C., Keller, J., Maillard, M.P., Hostettmann, K., 1997. A lanostane-type steroid from the fungus Ganoderma carnosum. Phytochemistry 46, 963-965.

Kendrick, B., 1985. The Fifth Kingdom. Mycologue Publication, Waterloo.

Kim, B.K., Cho, H.Y., Kim, J.S., Kim, H.W., Choi, E.C., 1993. Studies on constituents of higher fungi of Korea (LXVIII). Antitumor components of the cultured mycelia of Ganoderma lucidum. Korean J. Pharmacol. 24, 203-212.

Kim, D.H., Shim, S.B., Kim, N.J., Jang, I.S., 1999. Beta-glucuronidaseinhibitory activity and hepatoprotective effect of Ganoderma lucidum. Biol. Pharm. Bull. 22, 162-164.

Kim, H.W., Kim, B.K., 1999a. Biomedicinal triterpenoids of Ganoderma lucidum (Curt.:Fr.) P. Karst. (aphyllophoromycetideae). Int. J. Med. Mush. 1, 121-138.

Kim, H.W., Shim, M.J., Choi, E.C., Kim, B.K., 1997. Inhibition of cytopathic effect of human immunodeficiency virus-1 by water-soluble extract of Ganoderma lucidum. Arch. Pharm. Res. 20, 425-431.

Kim, K.C., Kim, I.G., 1999b. Ganoderma lucidum extract protects DNA from strand breakage caused by hydroxyl radical and UV irradiation. Int. J. Mol. Med. 4, 273-277.

Kim, S.W., Hwang, H.J., Xu, C.P., Sung, J.M., Choi, J.W., Yun, J.W., 2003. Optimization of submerged culture process for the production of mycelial biomass and exo-polysaccharides by Cordyceps militaris C738. J. Appl. Microbiol. 94, 120-126.

Kim, Y.S., Eo, S.K., Oh, K.W., Lee, C., Han, S.S., 2000. Antiherpetic activities of acidic protein bound polysaccharide isolated from Ganoderma lucidum alone and in combinations with interferons. J. Ethnopharmacol. 72, 451-458.

Kimura, Y., Taniguchi, M., Baba, K., 2002. Antitumor and antimetastatic effects on liver of triterpenoid fractions of Ganoderma lucidum: mechanism of action and isolation of an active substance. Anticancer Res. 22, 3309-3318.

Kleinwächter, P., Anh, N., Kiet, T.T., Schlegel, B., Dahse, H.M., Hartl, A., Grafe, U., 2001. Colossolactones, new triterpenoid metabolites from a Vietnamese mushroom Ganoderma colossum. J. Nat. Prod. 64, 236-239.

Komoda, Y., Shimizu, M., Sonoda, Y., Sato, Y., 1989. Ganoderic acid and its derivatives as cholesterol synthesis inhibitors. Chem. Pharm. Bull. (Tokyo) 37, 531-533.

Korf, R.P., 2005. Reinventing taxonomy: a curmudgeon's view of 250 years of fungal taxonomy, the crises in biodiversity, and the pitfalls of the phylogenetic age. Mycotaxon 93, 407-415.

Kuo, M.-C., Weng, C.-Y., Ha, C.-L., Wu, M.-J., 2006. Ganoderma lucidum mycelia enhance innate immunity by activating NF- $\mathrm{BB}$. J. Ethnopharmacol. 103, 217-222.

Lee, J.M., Kwon, H., Jeong, H., Lee, J.W., Lee, S.Y., Baek, S.J., Surh, Y.J., 2001. Inhibition of lipid peroxidation and oxidative DNA damage by Ganoderma lucidum. Phytother. Res. 15, 245-249.

Lee, S., Park, S., Oh, J.W., Yang, C., 1998. Natural inhibitors for protein prenyltransferase. Planta Med. 64, 303-308.

Lei, L.S., Lin, Z.B., 1992. Effect of Ganoderma polysaccharides on T cell subpopulations and production of interleukin 2 in mixed lymphocyte response. Acta Pharmaceut. Sin. 27, 331-335.

Lei, L.S., Lin, Z.B., 1993. Effects of Ganoderma polysaccharides on the activity of DNA polymerase alpha of splenocytes and immune function in aged mice. Acta Pharmaceut. Sin. 28, 577-582.

Leonowicz, A., Matusjewska, A., Luterek, J., Ziegenhagen, D., WojtasWasilewska, M., Cho, N.-S., Hofrichter, M., Roglaski, J., 1999. Biodegradation of lignin by white rot fungi. Fungal Genet. Biol. 27, 175-185. 
Li, C.-H., Chen, P.-Y., Chang, U.-M., Kan, L.-S., Fang, W.-H., Tsai, K.S., Lin, S.-B., 2005. Ganoderic acid X, a lanostanoid triterpene, inhibits topoisomerases and induces apoptosis of cancer cells. Life Sci. 77, 252-265.

Li, M.C., Liang, D.S., Xu, Z.M., Lei, L.S., Yang, S.Q., 2000. Effect of Ganoderma polysaccharides on cAMP in murine peritoneal macrophages. Zhongguo Zhong Yao Za Zhi 25, 41-43.

Li, P., Zhang, K., 2000. Isolation, purification and bioactivities of exopoly saccharides from fermented broth of Ganoderma lucidum. Wei Sheng Wu Xue Bao 40, 217-220.

Lieu, C.W., Lee, S.S., Wang, S.Y., 1992. The effect of Ganoderma lucidum on induction of differentiation in leukemic U937 cells. Anticancer Res. 12, 1211-1215.

Lin, C.-N., Fann, Y.-F., Chung, M.-I., 1997. Steroids of formosan Ganoderma tsugae. Phytochemistry 46, 1143-1146.

Lin, C.-N., Kuo, S.-H., Won, S.-J., 1993. Steroids of formosan Ganoderma amboinense. Phytochemistry 32, 1549-1551.

Lin, C.N., Tome, W.P., Won, S.J., 1991. Novel cytotoxic principles of Formosan Ganoderma lucidum. J. Nat. Prod. 54, 998-1002.

Lin, J.M., Lin, C.C., Chen, M.F., Ujiie, T., Takada, A., 1995. Radical scavenger and antihepatotoxic activity of Ganoderma formosanum, Ganoderma lucidum and Ganoderma neo-japonicum. J. Ethnopharmacol. 47, 33-41.

Lin, J.-Y., Chen, M.-L., Chiang, B.-L., Lin, B.-F., 2006. Ganoderma tsugae supplementation alleviates bronchoalveolar inflammation in an airway sensitization and challenge mouse model. Int. Immunopharmacol. 6, 241-251.

Lin, L.J., Shiao, M.S., 1987. Separation of oxygenated triterpenoids from Ganoderma lucidum by high-performance liquid chromatography. J. Chromatogr. 410, 195-200.

Lin, S.B., Li, C.H., Lee, S.S., Kan, L.S., 2003. Triterpene-enriched extracts from Ganoderma lucidum inhibit growth of hepatoma cells via suppressing protein kinase $\mathrm{C}$, activating mitogen-activated protein kinases and G2-phase cell cycle arrest. Life Sci. 72, 2381-2390.

Lindequist, U., 1995. Structure and biological activity of triterpenes, polysaccharides and other constituents of Ganoderma lucidum. In: Kim, B.K., Kim, I.H., Kim, Y.S. (Eds.), Proceedings of the 6th International Symposium on Recent Advances in Ganoderma lucidum Research. The Pharmaceutical Society of Korea, Seoul, pp. 6191.

Liu, J., Shimizu, K., Konishi, F., Noda, K., Kumamoto, S., Kurashiki, K., Kondo, R., in press. Anti-androgenic activities of the triterpenoids fraction of Ganoderma lucidum. Food Chem.

Lu, Q.-Y., Jin, Y.-S., Zhang, Q., Zhang, Z., Heber, D., Go, V.L.W., Li, F.P., Rao, J.Y., 2004. Ganoderma lucidum extracts inhibit growth and induce actin polymerization in bladder cancer cells in vitro. Cancer Lett. 216, 9-20.

Mau, J.-L., Tsai, S.-Y., Tseng, Y.-H., Huang, S.-J., 2005a. Antioxidant properties of methanolic extracts from Ganoderma tsugae. Food Chem. 93, 641-649.

Mau, J.-L., Tsai, S.-Y., Tseng, Y.-H., Huang, S.-J., 2005b. Anti oxidant properties of hot water extracts from Ganoderma tsugae Murrill. LWT - Food Sci.Technol. 38, 589-597.

Miller, R.N.G., Holderness, M., Bridge, P.D., Paterson, R.R.M., Sariah, M., Hussin, M.D.Z., Hilsey, E.J., 1995. A multi-disciplinary approach to the characterisation of Ganoderma in oil-palm cropping systems. In: Buchanan, P.K., Hsea, R.S., Moncalvo, J.M. (Eds.), Proceedings of the Contributed Symposium 59; Fifth International Mycological Congress, Vancouver, pp. 57-66.

Min, B.S., Gao, J.J., Hattori, M., Lee, H.K., Kim, Y.H., 2001. Anticomplement activity of terpenoids from the spores of Ganoderma lucidum. Planta Med. 67, 811-814.

Min, B.S., Nakamura, N., Miyashiro, H., Bae, K.W., Hattori, M., 1998. Triterpenes from the spores of Ganoderma lucidum and their inhibitory activity against HIV-1 protease. Chem. Pharm. Bull. (Tokyo) 46, 1607-1612.

Mizuno, T., 1997. Studies on bioactive substances and medicinal effect of Reishi, Ganoderma lucidum in Japan. In: Proceedings of the 1st
International Symposium on Ganoderma lucidum in Japan, ToyoIgaku-sha Co. Ltd., Tokyo, pp. 121-127.

Mizushina, Y., Takahashi, N., Hanashima, L., Koshino, H., Esumi, Y., Uzawa, J., Sugawara, F., Sakaguchi, K., 1999. Lucidenic acid O and lactone, new terpene inhibitors of eukaryotic DNA polymerases from a basidiomycete, Ganoderma lucidum. Bioorg. Med. Chem. 7, 2047-2052.

Mizushina, Y., Watanabe, I., Togashi, H., Hanashima, L., Takemura, M., Ohta, K., Sugawara, F., Koshino, H., Esumi, Y., Uzawa, J., Matsukage, A., Yoshida, S., Sakaguchi, K., 1998. An ergosterol peroxide, a natural product that selectively enhances the inhibitory effect of linoleic acid on DNA polymerase beta. Biol. Pharm. Bull. 21, $444-448$.

Morigiwa, A., Kitabatake, K., Fujimoto, Y., Ikekawa, N., 1986. Angiotensin converting enzyme-inhibitory triterpenes from Ganoderma lucidum. Chem. Pharm. Bull. (Tokyo) 34, 3025-3028.

Mothana, R.A., Jansen, R., Julich, W.D., Lindequist, U., 2000. Ganomycins $\mathrm{A}$ and $\mathrm{B}$, new antimicrobial farnesyl hydroquinones from the basidiomycete Ganoderma pfeifferi. J. Nat. Prod. 63, 416-418.

Mothana, R.A.A., Awadh Ali, N.A., Jansen, R., Wegner, U., Mentel, R., Lindequist, U., 2003. Antiviral lanostanoid triterpenes from the fungus Ganoderma pfeifferi. Fitoterapia 74, 177-180.

Müller, C.I., Kumagai, T., O'Kelly, J., Seeram, N.P., Heber, D., Koeffler, H.P., 2006. Ganoderma lucidum causes apoptosis in leukemia, lymphoma and multiple myeloma cells. Leuk. Res. 30, 841-848.

Ngai, P.H.K., Ng, T.B., 2004. A mushroom (Ganoderma capense) lectin with spectacular thermostability, potent mitogenic activity on splenocytes, and antiproliferative activity toward tumor cells. Biochem. Biophys. Res. Commun. 314, 988-993.

Nishitoba, T., Sato, H., Sakamura, S., 1987. Triterpenoids from the fungus Ganoderma lucidum. Phytochemistry 26, 1777-1784.

Nishitoba, T., Sato, H., Shirasu, S., Sakamura, S., 1986. Evidence on the strainspecific terpenoid pattern of Ganoderma lucidum. Agric. Biol. Chem. 50, 2151-2154.

Noguchi, M., Kakuma, T., Tomiyasu, K., Konishi, F., Kumamoto, S., Kondo, R., Matsuoka, K., 2005. Phase I study of a methanol extract of Ganoderma lucidum, edible and medicinal mushroom, in men with mild symptoms of bladder outlet obstruction. Urology 66, 121.

Ofodile, L.N., Uma, N.U., Kokubun, T., Ogundipe, O.T., Simmonds, M.S.J., 2005. Antimicrobial activity of some Ganoderma species from Nigeria. Phytother. Res. 19, 310-313.

Oh, K.W., Lee, C.K., Kim, Y.S., Eo, S.K., Han, S.S., 2000. Antiherpetic activities of acidic protein bound polysaccharide isolated from Ganoderma lucidum alone and in combinations with acyclovir and vidarabine. J. Ethnopharmacol 72, 221-227.

Ooi, L.S.M., Ooi, V.E.C., Fung, M.C., 2002. Induction of gene expression of immunomodulatory cytokines in the mouse by a polysaccharide from Ganoderma lucidum (Curt.: Fr.) P. Karst. (aphyllophoromycetideae). Int. J. Med. Mush. 4, 27-35.

Park, E.J., Ko, G., Kim, J., Sohn, D.H., 1997. Antifibrotic effects of a polysaccharide extracted from Ganoderma lucidum, glycyrrhizin, and pentoxifylline in rats with cirrhosis induced by biliary obstruction. Biol. Pharm. Bull. 20, 417-420.

Paterson, R.R.M., 2005. The coronamycin producer: a case of mistaken identity? Mycol. Res. 109, 850-851.

Peng, Y., Zhang, L., Zeng, F., Kennedy, J.F., 2005. Structure and antitumor activities of the water-soluble polysaccharides from Ganoderma tsugae mycelium. Carbohyd. Polym. 59, 385-392.

Pero, R.W., Amiri, A., Sheng, Y., Welther, M., Rich, M., 2005. Formulation and in vitro/in vivo evaluation of combining DNA repair and immune enhancing nutritional supplements. Phytomedicine $12,255-263$.

Ripperger, H., Budzikiewicz, H., 1975. Steroide aus Ganoderma applanatum. Phytochemistry 14, 2297-2298.

Roberts, L.M., 2004. Austalian Ganoderma: Identification, Growth and Antibacterial Properties. Ph.D. Thesis, Swinburne University of Technology, Australia.

Rösecke, J., König, W.A., 2000. Constituents of various wood-rotting basidiomycetes. Phytochemistry 54, 603-610. 
Sasaki, T., Arai, Y., Ikekawa, T., Chihara, G., Fukuoka, F., 1971. Antitumor polysaccharides from some polyporaceae, Ganoderma applanatum (Pers.) Pat and Phellinus linteus (Berk. et Curt) Aoshima. Chem. Pharm. Bull. (Tokyo) 19, 821-826.

Shiao, M.S., 1992. Triterpenoid natural products in the fungus Ganoderma lucidum. J. Chin. Chem. Soc. 39, 669-674.

Shiao, M.-S., Lin, L.-J., Yeh, S.-F., 1988. Triterpenes in Ganoderma lucidum. Phytochemistry 27, 873-875.

Shieh, Y.H., Liu, C.F., Huang, Y.K., Yang, J.Y., Wu, I.L., Lin, C.H., Li, S.C., 2001. Evaluation of the hepatic and renal-protective effects of Ganoderma lucidum in mice. Am. J. Chin. Med. 29, 501-507.

Shim, S.H., Ryu, J., Kim, J.S., Kang, S.S., Xu, Y., Jung, S.H., Lee, Y.S., Lee, S., Shin, K.H., 2004. New lanostane-type triterpenoids from Ganoderma applanatum. J. Nat. Prod. 67, 1110-1113.

Shimizu, A., Yano, T., Saito, Y., Inada, Y., 1985. Isolation of an inhibitor of platelet aggregation from a fungus, Ganoderma lucidum. Chem. Pharm. Bull. (Tokyo) 33, 3012-3015.

Sliva, D., 2006. Ganoderma lucidum in cancer research. Leuk. Res. 30, $767-768$.

Smania, A.J., Delle Monache, F., Smania, E.F.A., Cuneo, R.S., 1999. Antibacterial activity of steroidal compounds isolated from Ganoderma applanatum (Pers.) Pat. (aphyllophoromycetideae) fruit body. Int. J. Med. Mush. 1, 325-330.

Smith, J.E., Rowan, N.J., Sullivan, R., 2002. Medicinal mushrooms: a rapidly developing area of biotechnology for cancer therapy and other bioactivities. Biotechnol. Let. 24, 1839-1845.

Sofni, C., Chairul, M., Hayashi, Y., 1994. Lanostanoid triterpenes from Ganoderma applanatum. Phytochemistry 35, 1305-1308.

Sone, Y., Okuda, R., Wada, N., Kishida, E., Misaki, A., 1985. Structures and antitumor activities of the polysaccharides isolated from fruiting body and the growing culture of mycelium of Ganoderma lucidum. Agric. Biol. Chem. 49, 2641-2653.

Song, C.H., Yang, B.K., Ra, K.S., Shon, D.H., Park, E.J., Go, G.I., Kim, Y.H., 1998. Hepatoprotective effect of extracellular polymer produced by submerged culture of Ganoderma lucidum WK-003. J. Microbiol. Biotechnol. 8, 277-279.

Strigina, L.I., Elkin, Y.N., Elyakov, G.B., 1971. Steroid metabolites of Ganoderma applanatum basidiomycete. Phytochemistry 10, 2361-2365.

$\mathrm{Su}$, C.H., Hsu, Y.H., 1995. A novel biomaterial containing chitin/1-3-bglucan from cell wall fungal genus Ganoderma for wound healing enhancer. In: 2nd Biomedical Materials and Technology Sympsosium, ROC, Taipei, p. 16.

Su, H.J., Fann, Y.F., Chung, M.I., Won, S.J., Lin, C.N., 2000. New lanostanoids of Ganoderma tsugae. J. Nat. Prod. 63, 514-516.

Sudirman, L.I., Mujiyati, S., 1997. Preliminary detection of antimicrobial activity of fruiting bodies' extracts of tropical Ganoderma sp.. In: Proceedings of the 1st International Symposium on Ganoderma lucidum in Japan. Toyo-Igaku-sha Co. Ltd., Tokyo, pp. 154-159.

Sun, J., He, H., Xie, B.J., 2004. Novel antioxidant peptides from fermented mushroom Ganoderma lucidum. J. Agric. Food Chem. 52, 6646-6652.

Stanley, G., Harvey, K., Slivova, V., Jiang, J., Sliva, D., 2005. Ganoderma lucidum suppresses angiogenesis through the inhibition of secretion of VEGF and TGF- $\beta 1$ from prostate cancer cells. Biochem. Biophys. Res. Commun. 330, 46-52.

Tanaka, S., Ko, K., Kino, K., Tsuchiya, K., Yamashita, A., Murasugi, A., Sakuma, S., Tsunoo, H., 1989. Complete amino acid sequence of an immunomodulatory protein, ling zhi-8 (LZ-8). An immunomodulator from a fungus, Ganoderma lucidium, having similarity to immunoglobulin variable regions. J. Biol. Chem. 264, 16372-16377.

Tasaka, K., Akagi, M., Miyoshi, K., Mio, M., Makino, T., 1988a. Antiallergic constituents in the culture medium of Ganoderma lucidum. (I) Inhibitory effect of oleic acid on histamine release. Agents Actions 23, $153-156$.
Tasaka, K., Mio, M., Izushi, K., Akagi, M., Makino, T., 1988b. Antiallergic constituents in the culture medium of Ganoderma lucidum. (II). The inhibitory effect of cyclooctasulfur on histamine release. Agents Actions 23, 157-160.

Timo, H., Niedermeyer, J., Lindequist, U., Mentel, R., Gördes, D., Schmidt, E., Thurow, K., Lalk, M., 2005. Antiviral terpenoid constituents of Ganoderma pfeifferi. J. Nat. Prod. 68, 1728-1731.

Tomoda, M., Gonda, R., Kasahara, Y., Hikino, H., 1986. Glycan structures of ganoderans b and c, hypoglycemic glycans of Ganoderma lucidum fruit bodies. Phytochemistry 25, 2817-2820.

Ukai, S., Kiho, T., Hara, C., Kuruma, I., Tanaka, Y., 1983. Polysaccharides in fungi. XIV. Anti-inflammatory effect of the polysaccharides from the fruit bodies of several fungi. J. Pharmacobiodyn. 6, 983-990.

van der Hem, L.G., van der Vliet, J.A., Bocken, C.F., Kino, K., Hoitsma, A.J., Tax, W.J., 1995. Ling Zhi-8: studies of a new immunomodulating agent. Transplantation 60, 438-443.

Wang, G., Zhang, J., Mizuno, T., Zhuang, C., Ito, H., Mayuzumi, H., Okamoto, H., Li, J., 1993. Antitumor active polysaccharides from the Chinese mushroom Songshan lingzhi, the fruiting body of Ganoderma tsugae. Biosci. Biotechnol. Biochem. 57, 894-900.

Wang, H., Ng, T.B., 2006. Ganodermin, an antifungal protein from fruiting bodies of the medicinal mushroom Ganoderma lucidum. Peptides 27, 27-30.

Wang, X.-M., Yang, M., Guana, S.-H., Liu, R.-X., Xia, J.-M., Bi, K.-S., Guoa, D.-A., 2006. Quantitative determination of six major triterpenoids in Ganoderma lucidum and related species by high performance liquid chromatography. J. Pharmaceut. Biomed. Anal. 41, 838-844.

Wu, T.S., Shi, L.S., Kuo, S.C., 2001. Cytotoxicity of Ganoderma lucidum triterpenes. J. Nat. Prod. 64, 1121-1122.

Yoon, S.Y., Eo, S.K., Kim, Y.S., Lee, C.K., Han, S.S., 1994. Antimicrobial activity of Ganoderma lucidum extract alone and in combination with some antibiotics. Arch. Pharm. Res. 17, 438-442.

Zhao, H.-B., Wang, S.-Z., He, Q.-H., Yuan, L., Chen, A.F., Lin, Z.-B., 2005. Ganoderma total sterol (GS) and $\mathrm{GS}_{1}$ protect rat cerebral cortical neurons from hypoxia/reoxygenation injury. Life Sci. 76, 1027-1037.

Zhang, H.N., Lin, Z.B., 2004. Hypoglycemic effect of Ganoderma lucidum polysaccharides. Acta Pharmacol. Sin. 25, 191-195.

Zhang, G.L., Wang, Y.H., Ni, W., Teng, H.L., Lin, Z.B., 2002. Hepatoprotective role of Ganoderma lucidum polysaccharide against BCG-induced immune liver injury in mice. World J. Gastroenterol. 8, 728-733.

Zhu, M., Chang, Q., Wong, L.K., Chong, F.S., Li, R.C., 1999. Triterpene antioxidants from Ganoderma lucidum. Phytother. Res. 13, $529-531$

Zhu, X., Lin, Z., 2006. Modulation of cytokines production, granzyme B and perforin in murine CIK cells by Ganoderma lucidum polysaccharides. Carbohyd. Polym. 63, 188-197.

Ziegenbein, F.C., Hanssen, H.-P., König, W.A., 2006. Secondary metabolites from Ganoderma lucidum and Spongiporus leucomallellus. Phytochemistry $67,202-211$.

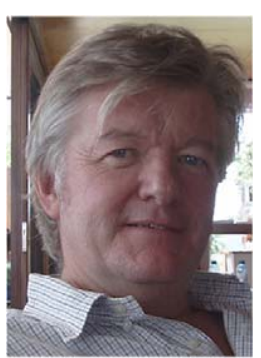

Russell Paterson is a research scientist at Centro de Engenharia Biológica, Micoteca da Universidade do Minho, Braga, Portugal. He obtained his $\mathrm{PhD}$ at the University of Manchester, UK in Professor J.D. BúLock's Microbial Chemistry Laboratory. He has held several posts subsequently including one at the Boyce Thompson Institute at Cornell University, New York. The secondary metabolism of fungi is his primary interest. 